De Sousa, E., Pimenta, E., Silva, E., Mendes, H., Arruda, A.M., Dorado-Alejos, A. (2020):

"Ânforas da Idade do Ferro e de tradição pré-romana do Porto do Sabugueiro (Muge, Portugal)", Spal 29.1: 129-156. DOI: http://dx.doi.org/10.12795/spal.2020.i29.05

\title{
ÂNFORAS DA IDADE DO FERRO E DE TRADIÇÃO PRÉ-ROMANA DO PORTO DO SABUGUEIRO (MUGE, PORTUGAL)
}

\section{IRON AGE AND PRE-ROMAN TRADITION AMPHORAE FROM PORTO DO SABUGUEIRO (MUGE, PORTUGAL)}

\author{
ELISA DE SOUSA \\ Responsable de la correspondencia \\ Universidade de Lisboa - Faculdade de Letras - Uniarq (Centro de Arqueologia) \\ Correo-e: e.sousa@campus.ul.pt. D https://orcid.org/0000-0003-3160-108X \\ Researcher ID: <https://publons.com/researcher/AAG-6086-2019> \\ JOÃO PIMENTA \\ Centro de Estudos Arqueológicos Vila Franca de Xira - CEAX \\ Correo-e: joao.marques@cm-vfxira.pt. D https://orcid.org/0000-0001-5149-5566 \\ Researcher ID: <https://publons.com/researcher/AAG-6215-2019> \\ INÊS SILVA \\ Mestranda em Arqueologia pela Faculdade de Letras da Universidade de Lisboa \\ Correo-e: inesdomingos1@campus.ul.pt. (D https://orcid.org/0000-0002-8779-7328 \\ Researcher ID: <https://publons.com/researcher/AAG-6469-2019> \\ HENRIQUE MENDES \\ Centro de Estudos Arqueológicos Vila Franca de Xira - CEAX \\ Correo-e: henriquecale@sapo.pt. (D) https://orcid.org/0000-0002-3416-8990 \\ Researcher ID: <https://publons.com/researcher/AAG-6988-2019> \\ ANA MARGARIDA ARRUDA \\ Universidade de Lisboa - Faculdade de Letras - Uniarq (Centro de Arqueologia). \\ Correo-e: a.m.arruda@letras.ulisboa.pt. (D) https://orcid.org/0000-0002-7446-1104 \\ Researcher ID: <https://publons.com/researcher/F-3570-2016> \\ ALBERTO DORADO-ALEJOS \\ Laboratorio de Arqueometría - Departamento de Prehistoria y Arqueología - Universidad de Granada (Espanha) \\ Correo-e: doradoalejos@ugr.es. D https://orcid.org/0000-0003-0351-7550 \\ Researcher ID: <https://publons.com/researcher/AAG-8112-2019>
}

Resumo: Durante as várias intervenções efectuadas no sítio do Porto do Sabugueiro foram recolhidas mais de duas centenas de fragmentos de ânforas da Idade do Ferro ou de tradição pré-romana. Trata-se de um conjunto importante no quadro regional, não só pela variedade tipológica das produções locais/regionais (tipos 1, 3, 4, 5, 6 e 7 do estuário do Tejo), mas também pela diversidade de fabricos identificados, revelando a complexidade das redes de produção e circulação dos recipientes anfóricos nesta área específica do território ocidental. A importância deste conjunto recai também na presença de um grupo considerável de materiais importados do sul da
Abstract: During the various interventions carried out on the site of Porto do Sabugueiro, more than two hundred amphora fragments of the Iron Age or pre-Roman tradition were collected. This is an important assemblage in the regional context, not only because of the typological variety of local / regional productions (Types 1, 3, 4, 5, 6 and 7 of the Tagus estuary) but also by the diversity of fabrics we were able to identify, revealing the complexity of the networks of production and circulation of amphorae containers inside the Tagus estuary. The importance of this set also lies in the presence of a considerable group of imported fragments from the south of 
Península Ibérica (ânforas dos tipos 10.1.1.1 de Ramon Torres, Pellicer B/C, Pellicer D e 8.1.1.2 de Ramon Torres), uma situação que não é frequente no contexto regional, e que é discutida com detalhe.

Palavras-chave: Atlântico, Tejo, $1^{\circ}$ milénio, comércio, produção, arqueometria.

\section{INTRODUÇÃO}

O Porto do Sabugueiro é um importante sítio arqueológico localizado no estuário do Tejo, mais especificamente no concelho de Salvaterra de Magos (fig. 1 e 2), freguesia de Muge (CNS - 2693), tendo sido identificado na década de 30 século passado, por Mendes Correa (Pimenta et al. 2014a).

Implanta-se na margem esquerda do rio Tejo, nas proximidades da vala de Alpiarça, numa área de baixa altitude que oscila entre os 5 e os 8 metros, tendo a zona um potencial agrícola considerável. Infelizmente, esta última característica foi também um dos factores que mais prejudicou a sua conservação. A presença de artefactos à superfície estende-se por uma área ampla, com cerca de 25 hectares, sendo muito difícil determinar se esta extensão está directamente relacionada com as suas dinâmicas de ocupação na Antiguidade (sobretudo desde a Idade do Ferro até ao período romano imperial), ou se é resultante da dispersão de materiais devido às intensas práticas agrícolas aí desde há muito realizadas (Pimenta et al. 2014a).

As intervenções arqueológicas que foram realizadas no Porto do Sabugueiro, efectuadas inicialmente por dois dos signatários (Pimenta e Mendes 2008, 2013) e posteriormente desenvolvidas no quadro do projecto de investigação FETE - Fenícios no Estuário do Tejo (PTDC/EPH-ARQ/4901/2012), financiado pela Fundação para a Ciência e a Tecnologia, permitiram constatar que o local foi, efectivamente, muito afectado pelas práticas agrícolas a que foi, e continua a ser, sujeito. Com efeito, os dados obtidos indicam que o potencial estratigráfico do sítio foi, quase na sua totalidade, irremediavelmente destruído (Pimenta et al. 2014a).

Ainda assim, os materiais recuperados quer em prospecção quer durante as várias campanhas de escavação, permitiram compreender que o espaço terá estado intensamente ocupado durante o $1^{\circ}$ milénio a.n.e. e as primeiras centúrias da nossa era, tendo revelado uma quantidade verdadeiramente extraordinária de the Iberian Peninsula (Ramon Torres type 10.1.1.1, type Pellicer B/C, type Pellicer D and Ramon Torres 8.1.1.2), which are not frequent in the regional context, and is discussed in detail.

Keywords: Atlantic, Tagus, $1^{\text {st }}$ millennium, trade, production, archaeometry.

artefactos dos diferentes períodos cronológicos, alguns dos quais já publicados (Pereira 1975, Pimenta e Mendes 2008, 2013, Pimenta et al. 2014a, Arruda et al. 2016, Pereira 2017, García Fernández 2019, Rodrigues et al. no prelo). Estes estudos indicam ainda que a sua ocupação proto-histórica se terá iniciado em torno ao século VII a.n.e., e que se prolongou, sem aparentes descontinuidades, até ao período romano imperial (Pimenta et al. 2014a).

Entre os vários materiais recuperados, cabe destacar a presença abundante de fragmentos de ânforas da Idade do Ferro e de tradição pré-romana que, apesar de não permitirem qualquer leitura contextual, apresentam particularidades que justificam um estudo mais detalhado, que será apresentado nas páginas seguintes. Cabe, porém, referir que neste estudo não se incluíram os recipientes que se enquadram claramente na época romana (republicana e imperial), ainda que várias das formas documentadas, que se relacionam com as tradições oleiras da Idade do Ferro da área do Tejo, tenham atingido também estes momentos mais tardios, concretamente do período romano-republicano (Sousa e Pimenta 2014), daí a utilização da expressão "de tradição pré-romana".

A importância do estudo que agora se apresenta reside sobretudo no facto de se terem identificado, entre os vários materiais, um conjunto muito significativo de contentores anfóricos que exibem características macroscópicas que indicam que se trata de produções locais, situação que parece ser agora corroborada com as análises radiométricas realizadas.

A identificação e compreensão da verdadeira complexidade e dimensão da produção de ânforas no estuário do Tejo é uma realidade que só recentemente tem sido valorizada (Sousa 2014, Sousa e Pimenta 2014), mas a verdade é que ainda nos faltam dados para compreendermos de forma mais detalhada os seus circuitos de fabrico e distribuição. O conjunto que agora se apresenta, ainda que não disponha de dados contextuais, é o terceiro mais numeroso conhecido em todo o estuário 


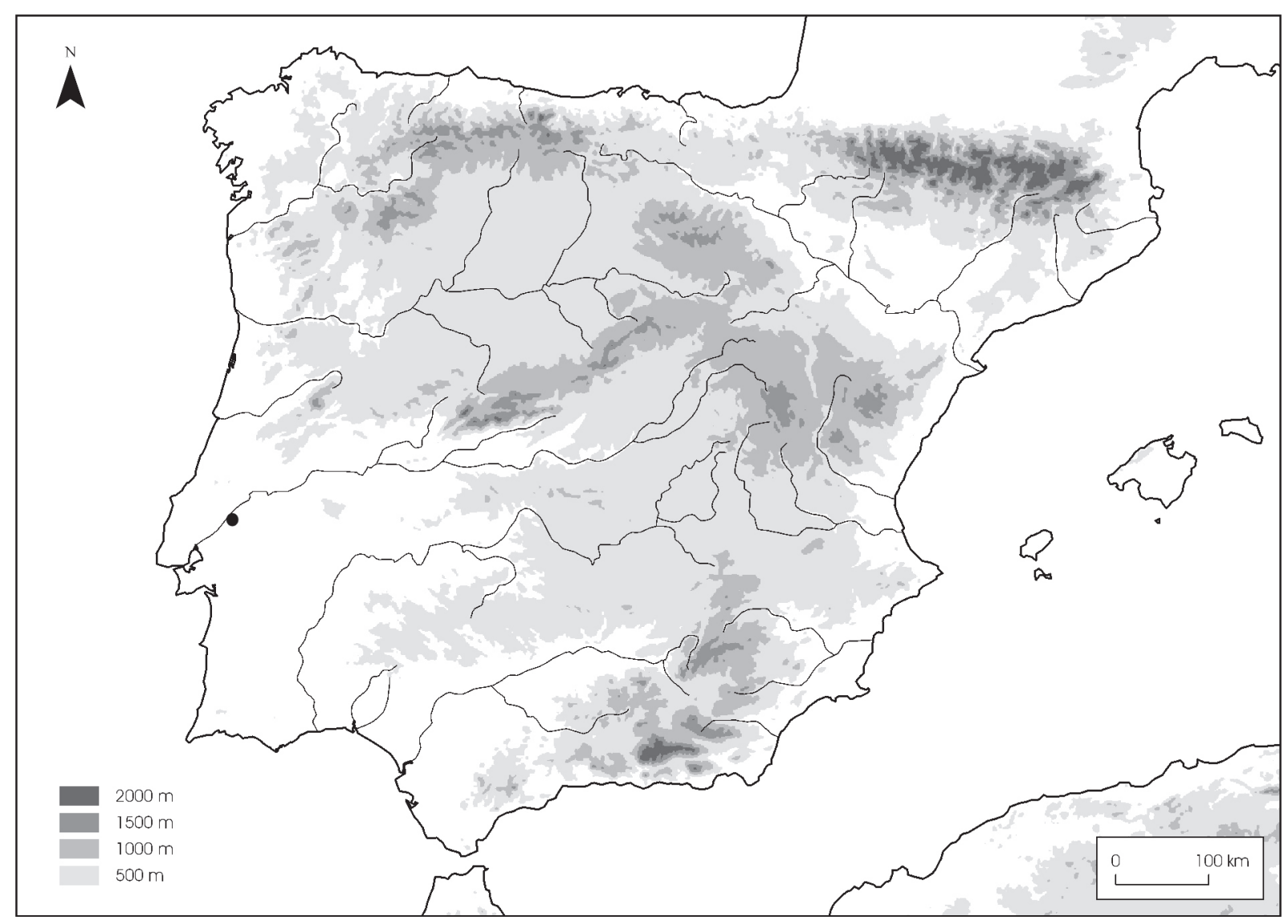

Figura 1. Localização do Porto do Sabugueiro no território peninsular.

do Tejo, depois do da Rua dos Correeiros, em Lisboa (Sousa 2014), e do da Quinta do Almaraz, Almada (Olaio 2018). Estes últimos, integrados na zona terminal da foz do Tejo, estão, muito provavelmente, nas proximidades dos respectivos centros produtores. A circulação destas produções anfóricas da área de Lisboa/ Almaraz chega também, e com muita expressividade, à região mais interior do curso do Tejo, como se verifica não só no Porto do Sabugueiro, mas também em outros sítios próximos como o Cabeço Guião (Arruda et al. 2017), Alto dos Cacos (Sousa et al. 2017), Alto do Castelo (Arruda et al. 2014) e Eira da Alorna (Pimenta et al. 2018). Contudo, a existência de uma outra área produtora de contentores anfóricos nesta zona mais interior, localizada muito provavelmente na própria zona do Porto do Sabugueiro (Sousa e Pimenta 2014), fornece contributos inestimáveis para a compreensão da complexidade destas redes distributivas. Desta forma, justifica-se a necessidade de procurar caracterizar, quer a nível formal, quer macroscópico e arqueométrico, estas produções mais interiores.
Um último aspecto que deve ser enfatizado é a identificação de um grupo bastante significativo de contentores anfóricos importados no conjunto do Porto de Sabugueiro, especialmente no contexto das realidades centro-atlânticas conhecidas até à data (Sousa 2017), e que mostram que este local, consideravelmente interior, esteve ligado, de certa forma, às redes comerciais das áreas mais meridionais da Península Ibérica ao longo de todo o $1^{\circ}$ milénio a.C.

\section{O CONJUNTO ANFÓRICO DO PORTO DO SABUGUEIRO}

Neste trabalho, incluem-se, portanto, os fragmentos de ânforas do Porto do Sabugueiro que estão relacionados, directa ou indirectamente, com o horizonte pré-romano. Como já foi anteriormente referido, a ausência de dados contextuais dificulta a atribuição de balizas cronológicas específicas para uma parte significativa destes materiais, não se podendo excluir a possibilidade 
de alguns (ou vários) poderem ter integrado a componente artefactual da fase romano-republicana. Contudo, apenas com a publicação mais detalhada de contextos desta cronologia no estuário do Tejo, e particularmente de materiais de tradição regional que acompanharam as importações itálicas e da Hispânia Ulterior que chegaram à região a partir do último terço do século II a.n.e., será possível determinar, com mais precisão, este tipo de pervivências e coexistências.

As várias intervenções efectuadas no Porto de Sabugueiro permitiram recuperar um total de 240 fragmentos de bordo de ânforas de cronologia ou tradição pré-romana, que foram sub-divididos em dois grandes grupos: os materiais de produção local e regional (231 exemplares), ou seja, da área do Estuário do Tejo, e os que parecem corresponder a importações das zonas mais meridionais do território peninsular (nove exemplares), alguns dos quais já publicados (García Fernández 2019: 137). A estes somam-se ainda dezenas de fragmentos de asas e alguns fundos, ainda que a informação que estes elementos proporcionem seja bastante limitada.

\subsection{As produções locais/regionais}

\subsubsection{Os grupos de fabrico}

Dentro dos exemplares que considerámos serem de origem local e regional, foi possível distinguir quatro grandes grupos de fabrico, um dos quais com características que justificaram uma ulterior subdivisão. Estes correspondem, grosso modo, a distinções e critérios já utilizados em estudos anteriores (Sousa e Pimenta 2014), ainda que a análise mais detalhada dos fragmentos recolhidos no Porto do Sabugueiro tenha permitido distinguir agora dois grupos distintos no quadro das produções da área mais interior do estuário do Tejo (grupos II e III), e um outro que parece ter origem numa zona mais próxima da foz (grupo IV). Dois fragmentos apresentavam ainda especificidades que justificaram a identificação do que definimos, dada a sua escassa representatividade, como fabricos raros A e B.

\subsubsection{Grupo I}

O primeiro grupo caracteriza-se por apresentar pastas compactas e com fractura regular, sendo o seu grau de depuração variável (entre 5\% e 20\%). Neste grupo, a análise macroscópica permitiu identificar a presença de moscovites, biotites, quartzos, plagióclase e calcites, sendo estas últimas particularmente abundantes. A coloração das pastas varia entre o castanho e o laranja, podendo por vezes mostrar também tonalidades acinzentadas, possivelmente devido aos processos de cozedura. Trata-se, muito provavelmente, de produções originárias da foz do estuário do Tejo, mais concretamente da zona de Lisboa/Almaraz.

Um elemento caracterizador deste grupo é a presença de microfósseis que, contudo, têm uma representatividade bastante variável que justificou a sub-divisão em dois fabricos distintos. O grupo I-A caracteriza-se pela presença frequente destes elementos; no grupo I-B os microfósseis são bastante mais raros.

Nas ânforas do Porto de Sabugueiro, o grupo I engloba 49 exemplares (distribuídos pelo fabrico I-A, com 26 fragmentos, e I-B, com 23 fragmentos), que corresponde a $21 \%$ do conjunto presentemente analisado.

\subsubsection{Grupo II}

O segundo grupo de fabrico reúne exemplares de pastas compactas e escassamente depuradas (superior a 20\%). A análise macroscópica permitiu identificar a presença frequente de partículas de quartzo, elementos carbonatados e também de desengordurantes de cerâmica moída em vários dos exemplares. Em termos de coloração, estes recipientes apresentam tons mais escuros, que variam entre o castanho e o cinzento. A considerável representatividade deste fabrico no Porto de Sabugueiro (61 exemplares - $26 \%$ do conjunto), assim como a sua escassez em outras áreas do estuário do Tejo, são elementos que poderão indicar uma origem local para estes recipientes.

\subsubsection{Grupo III}

O grupo III inclui fragmentos de pastas mediamente compactas e pouco depuradas (20\%). A observação macroscópica permitiu a identificação de elementos de quartzos, por vezes de grande dimensão, e algumas moscovites. As suas tonalidade são geralmente acastanhadas, podendo por vezes apresentar tons mais acinzentados. Estas características são semelhantes às do grupo anterior (grupo II), ainda que se note um maior cuidado na produção e preparação das pastas. Ainda assim, é muito provável que corresponda também a uma produção local ou das proximidades, devendo, neste aspecto, assinalar-se a grande semelhança revelada nos dados arqueométricos (ver 2.1.2).

No conjunto aqui analisado, este grupo inclui 65 exemplares, correspondendo a $28 \%$. 


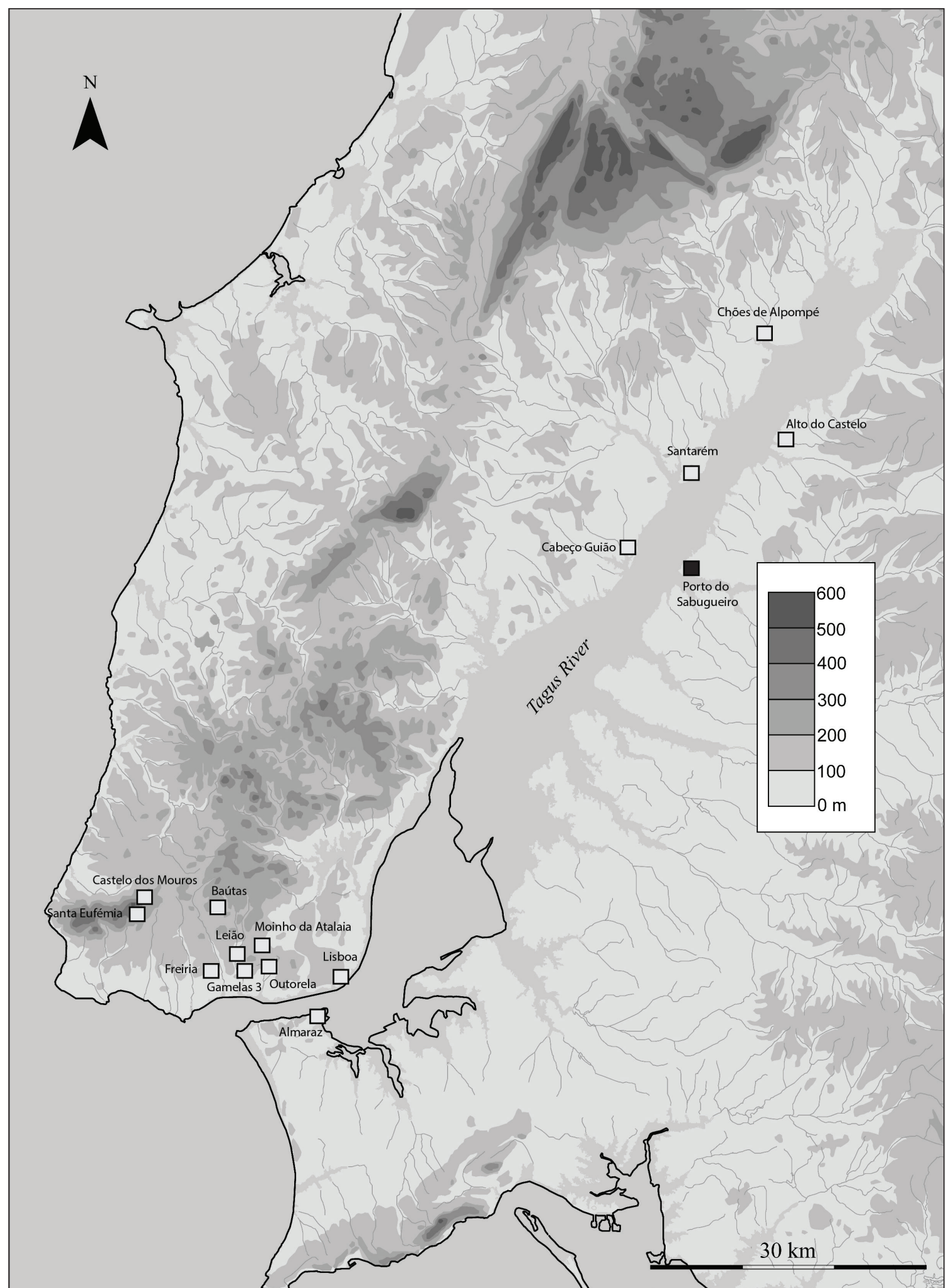

Figura 2. Localização do Porto do Sabugueiro (a negro) e dos principais núcleos de povoamento do Estuário do Tejo durante a Idade do Ferro (séculos V a III a.n.e.).

ISSN: 1133-4525 ISSN-e: 2255-3924 


\subsubsection{Grupo IV}

O grupo IV integra peças de pastas bastante compactas e relativamente depuradas (entre 10 e $20 \%$ ). A observação macroscópica permitiu a identificação de abundantes elementos de quartzos, calcites, moscovites e desengordurantes avermelhados, possivelmente de cerâmica moída, mas também de óxidos de ferro. Cabe ainda indicar a presença de microfósseis, identificáveis macroscopicamente. As suas tonalidades são tendencialmente alaranjadas, ainda que por vezes apresentem um núcleo acinzentado. Estas características parecem quase representar uma produção "intermédia" entre os dois grupos anteriormente definidos (II e III) e os fabricos típicos da zona de Lisboa/Almaraz (Grupo I-A e I-B). Ainda que não se possa excluir completamente a possibilidade de ser uma produção um pouco mais interior, a macroscopia e as análises arqueométricas parecem indicar uma proveniência próxima da proposta para o Grupo I, quiçá ligeiramente mais interior, considerando que os materiais do Grupo IV são, efectivamente, menos depurados. Contudo, esta questão só poderá ser definitivamente resolvida através da identificação dos respectivos centros produtores.

Os fragmentos integrados no grupo IV totalizam 50 peças, correspondendo a $23 \%$.

\subsubsection{Fabrico raro $A$}

Neste grupo integra-se apenas um exemplar (1\% do conjunto), cujas características são bastante semelhantes às do grupo III, mas que exibe uma pasta bastante mais depurada e uma tonalidade cinzenta acastanhada, ainda que esta se deva, quase seguramente, a variações no quadro do processo de cozedura do recipiente.

\subsubsection{Fabrico raro $B$}

Também neste caso contamos com apenas um fragmento ( $1 \%$ do conjunto), que se distingue por apresentar uma pasta de tonalidade castanha amarelada, com presença frequente de micas, ainda que seja, em termos gerais, semelhante aos exemplares do grupo III.

\subsubsection{Análises arqueométricas}

A definição de grupos de fabrico com base na mera análise macroscópica tem, naturalmente, fortes limitações sobretudo ao nível da caracterização das inclusões e desengordurantes que fazem parte das pastas cerâmicas
(De la Fuente e Vera 2015: 265, nota 3). Por essa razão, os elementos definidos macroscopicamente terão de ser confirmados por futuros estudos mineralógicos e petrográficos. Ainda assim, e com o objectivo de complementar as divisões anteriormente esboçadas, foi realizada uma primeira aproximação da composição química de alguns dos exemplares, sobretudo daqueles que foram considerados como possíveis produções das áreas mais interiores do estuário do Tejo (grupos macroscópicos II e III), assim como de outros aparentemente mais próximos da foz (grupo IV). Assim, foram recolhidas 16 amostras do conjunto anfórico recolhido no Porto do Sabugueiro (tab. 1). Para determinar ou corroborar as origens propostas para estas produções foram incluídas no espectro de análise outras sete amostras recolhidas em outros sítios localizados na região do Tejo, concretamente do Cabeço Guião (Arruda et al. 2017), Lisboa (Sousa e Guerra 2018) e da Alcáçova de Santarém (Arruda 2000, Sousa e Arruda 2018), alguns dos quais provenientes de zonas mais interiores, e outros provavelmente originários da área da foz (Lisboa/Almaraz).

A metodologia utilizada recorreu a um analisador pXRF Niton XL3t de PANATEC com tubo de raio-x 50 $\mathrm{kV}$ e 100 microamperes. O filtro usado foi o Soils, de dois feixes, a 60 " por feixe para um total de 120". Cada modo opera com uma voltagem diferente, que aperfeiçoa a fluorescência de um conjunto de elementos e seleciona diferentes filtros para otimizar as relações de pico/fundo. Essa técnica permitiu-nos quantificar os seguintes elementos: Mo, Zr, Sr, U, Rb, Th, Pb, As, Zn, $\mathrm{Cu}, \mathrm{Fe}_{2} \mathrm{O}_{3}, \mathrm{MnO}, \mathrm{Cr}, \mathrm{V}, \mathrm{TiO}_{2}, \mathrm{CaO}$ e $\mathrm{K}_{2} \mathrm{O}$. Estes resultados foram tratados estatisticamente pela Análise de Componentes Principais (ACP) (Aitchison 1983, 1984, Whallon 1990, Glasckoc 1992, Baxter 1994, 2003), uma análise estatística muito útil para interpretar a relação entre diferentes produções cerâmicas (Gómez Siurana 1987, Galván Martínez 1995, Carmona et al. 2008, Aldazábal et al. 2010, entre outros).

Os resultados obtidos permitiram confirmar a relativa homogeneidade já verificada na análise macroscópica das produções anfóricas deste importante núcleo de povoamento no interior do estuário do Tejo (fig. 3).

No grupo composto pelas amostras 1703, 1681, $1545,1608,1623,1561$ e 1711, todas fazendo parte dos grupos macroscópicos previamente estabelecidos como II e III, observa-se uma certa homogeneidade relativa (fig. 4). Este primeiro grupo apresenta os menores valores dos elementos maioritários, sendo estes $\mathrm{Fe}_{2} \mathrm{O}_{3}$ (33349 ppm), $\mathrm{TiO}_{2}$ (4420 ppm), $\mathrm{CaO}$ (9232 ppm) e $\mathrm{K}_{2} \mathrm{O}$ (23336 ppm), em relação aos demais agrupamentos, 


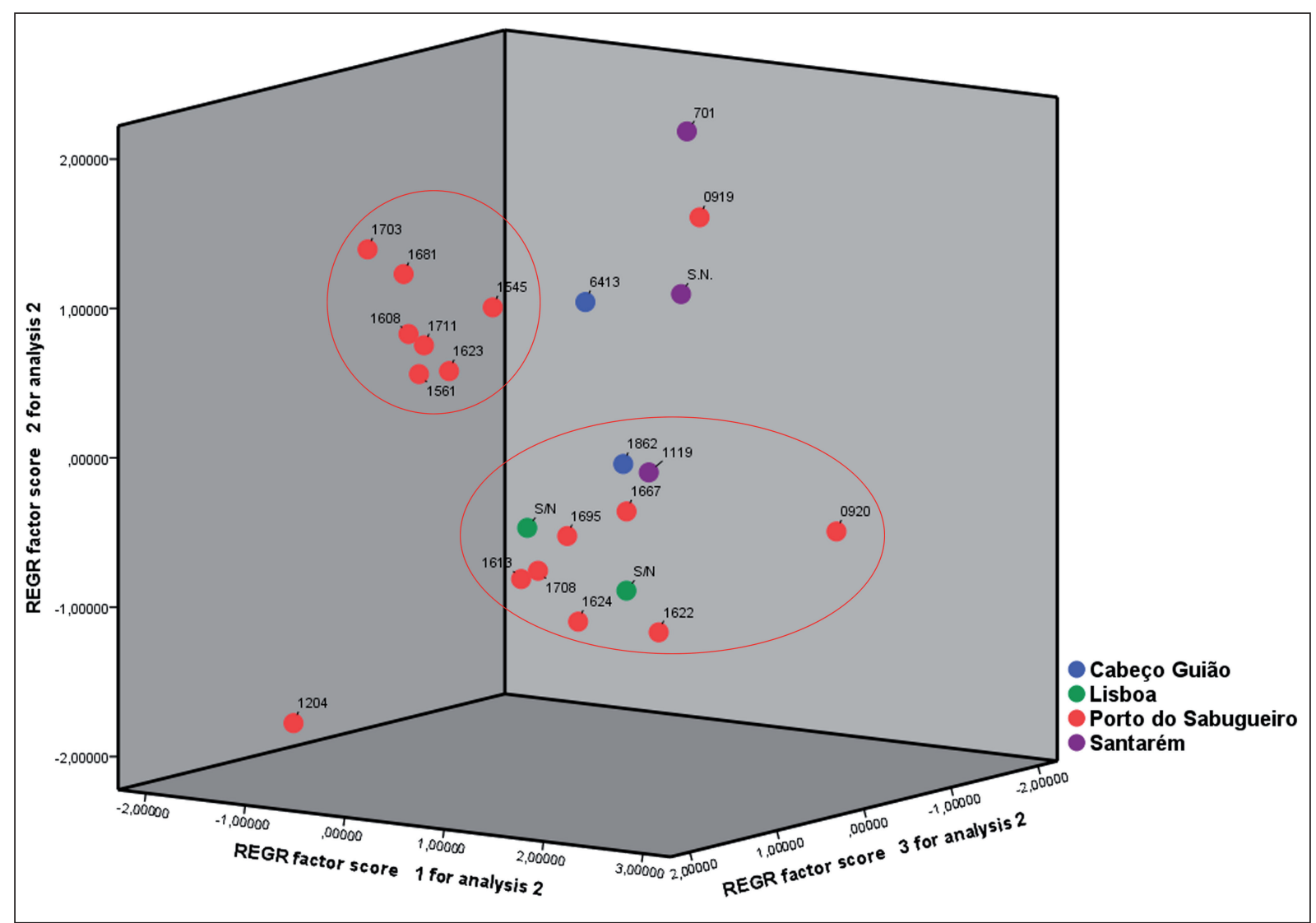

Figura 3. Representação no diagrama de dispersão 3D dos três factores extraídos da Análise de Componentes Principais.

sendo $\mathrm{MnO}$ (388) o mais elevado do conjunto. Os restantes elementos são ordenados, de acordo com a sua presença, como segue: $\mathrm{Sr}$ (191 ppm), Zr (184 ppm), Rb (157 ppm), V (123 ppm), Zn (115.07 ppm), Cr (72 ppm), Pb (23 ppm), Cu (15ppm), Th (14 ppm), As (12 ppm), U (4 ppm) e Mo (3 ppm). Os dados permitem propor que tanto a extração como o tratamento das matérias-primas realizado pelos oleiros locais são similares. Estas produções apresentam, com frequência, tons acinzentados na zona do núcleo, de caráter redutor, enquanto suas zonas externas são de tons bege e alaranjado, de eminente cozedura redutiva. A falta de uma preparação ideal de matérias-primas levou à presença de desengordurantes de pequena dimensão, que foram identificados como quartzo, micas e restos de matéria vegetal, em quantidades que variam entre 10 e $30 \%$ do total das argilas. Além disso, sua morfologia é sub-arredondada, ou seja, apresentam uma alta taxa de erosão que pode estar ligada a contribuições aluviais e de desengordurantes que são orientadas de forma paralela/ oblíqua em relação às paredes, como consequência de sua modelagem a torno. Finalmente, queremos realçar a presença de pequenos poros que estão relacionados com a fase de secagem, que às vezes se transformam em estrias que correm na mesma direção das paredes.

Um segundo grupo incorpora as amostras 920, $1622,1624,1708,1613,1695$ e 1667 que foram englobadas no grupo macroscópico IV (fig. 5). Este conjunto apresenta certas variações nas quantidades dos elementos maioritários, de modo que tem uma maior presença de $\mathrm{Fe}_{2} \mathrm{O}_{3}$ (37852), $\mathrm{TiO}_{2}$ (5211.04) e $\mathrm{K}_{2} \mathrm{O}$ (28912), sendo inferior em MnO (131). Também observamos certas variações nos restantes elementos, que são ordenados, de acordo com sua presença, conforme segue: $\mathrm{Zr}$ (163), Rb (160), V (151), Sr (128), Cr (118), $\mathrm{Zn}$ (109), Pb (21), Cu (15), Th (13), As (8), U (6) e Mo (3). Ainda que relativamente próximas das anteriores, estas amostram formam um agrupamento bastante homogéneo, estando muito próximas de outros fragmentos recolhidos em Lisboa, Santarém e Cabeço Guião, e cujas características macroscópicas indiciam uma produção originária na foz do estuário (zona de Lisboa/ 

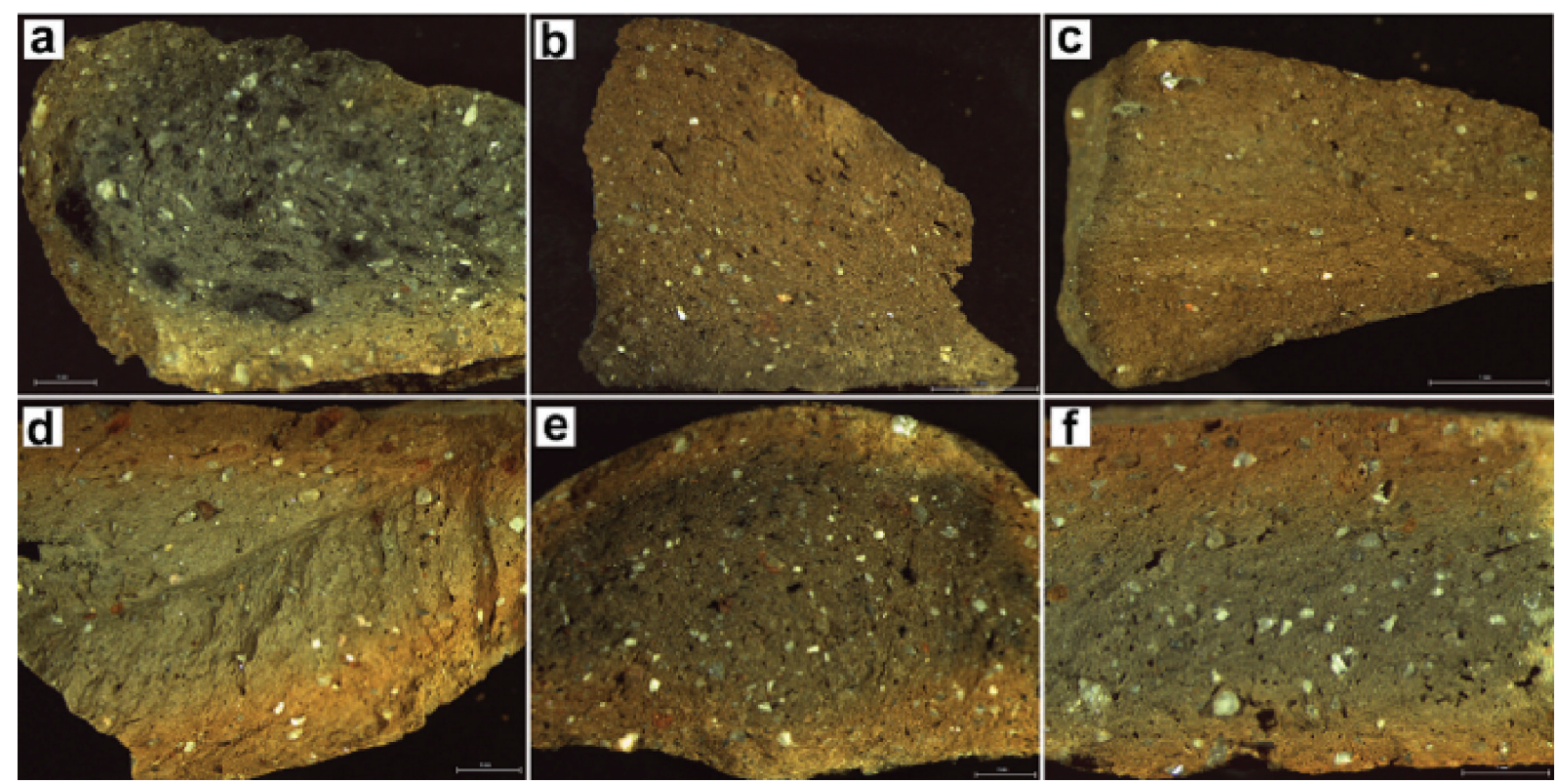

Figura 4. Conjunto de amostras correspondentes às produções consideradas originárias do interior do estuário identificadas pelo pFRX: a) 1703 (grupo II); b) 1681 (grupo II); c) 1545 (grupo II); d) 1608 (grupo III); e) 1711 (grupo II); f) 1623 (grupo III).

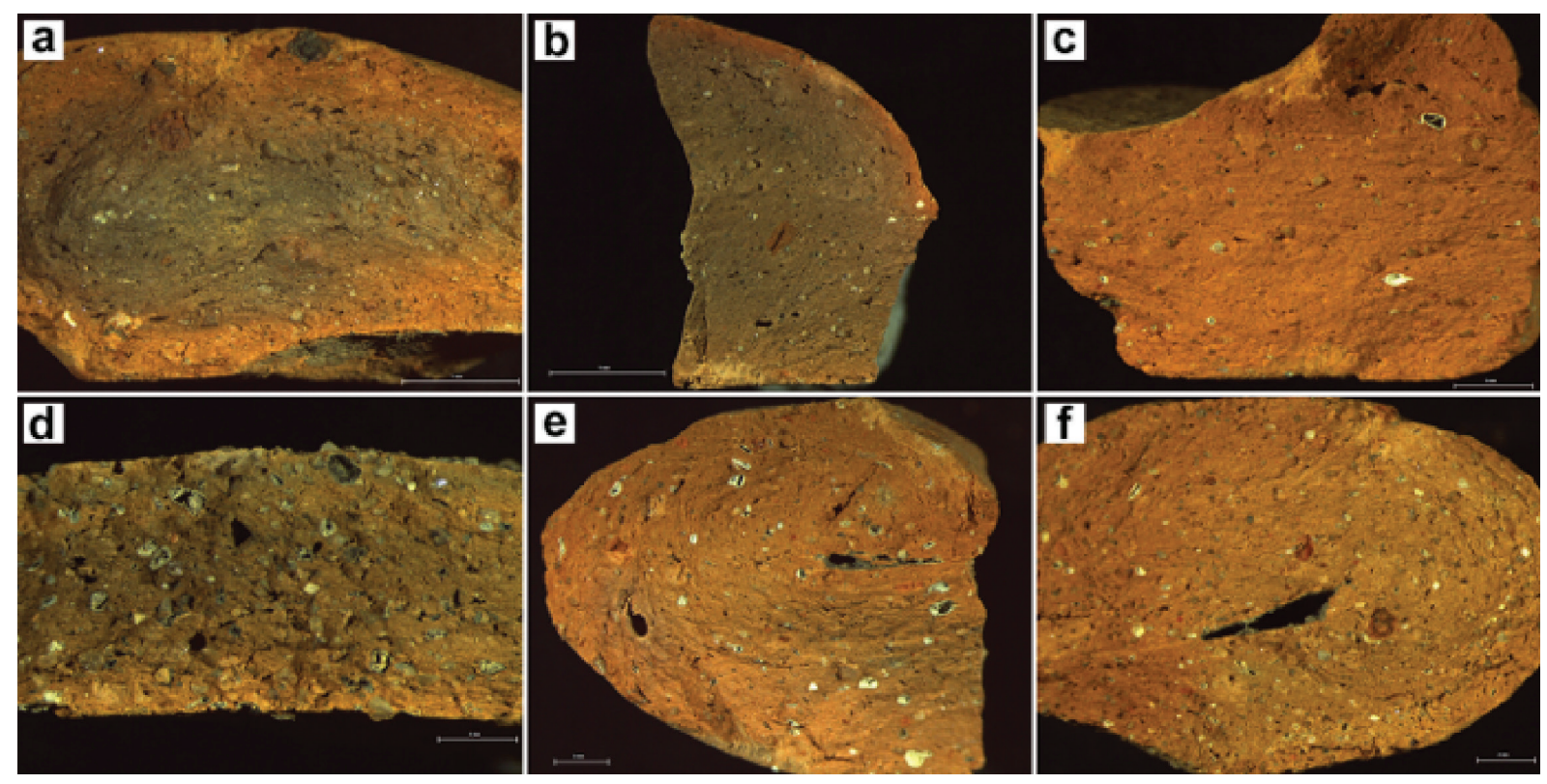

Figura 5. Conjunto de correspondentes às produções consideradas originárias junto à foz do estuário (grupo IV) identificadas pelo pFRX: a) 920; b) 1622; c) 1624; d) 1708; e) 1613; f) 1695.

Almaraz). A aproximação macroscópica feita neste conjunto permite apontar certas variações de tonalidade em relação aos grupos anteriores (II e III), que são agora mais alaranjadas e com tonalidades mais regulares na matriz cerâmica. Em termos gerais, trata-se de produções mais refinadas, com menor presença de desengordurantes, localizadas em torno de 10 a $15 \%$ do total de matérias-primas, de modo que determinados processos de tratamento pudessem ser deduzidos (Coll Conesa 2000). Esse conjunto apresenta, portanto, um 
cozimento geralmente oxidante e no qual se observa uma certa regularidade no desenvolvimento das estratégias de cozedura. As inclusões identificadas foram o quartzo, micas e alguns foraminíferos, que devem ser encontrados nas matérias-primas. Além disso, destacam-se pequenos nódulos de argila que deveriam ter sido adicionados ao grupo de matérias-primas durante os diversos processos de tratamento prévio à cozedura. Os desengordurantes, como no caso anterior, apresentam uma alta esfericidade e, portanto, devem ser entendidos como elementos de matérias-primas do contexto aluvial, em que a erosão teria definido a sua morfologia final. Da mesma forma, e como consequência do uso do torno no processo de modelagem, esses desengordurantes foram orientados preferencialmente de maneira oblíqua/paralela em relação às paredes. Por fim, percebe-se que os possuem uma morfologia vesicular e, em casos raros, possuem sulcos que são orientados no mesmo sentido que as paredes dos contentores como consequência da contração de argilas durante a secagem/cozedura.

Estes resultados permitem, assim, confirmar ou corroborar a existência de intensas relações comerciais entre diferentes núcleos de povoamento no interior do estuário do Tejo. No entanto, é necessário, no futuro, aumentar o universo de amostras dos vários sítios, quer do próprio Porto de Sabugueiro, como dos restantes locais situados nos seus arredores.

Um outro resultado interessante é demonstrado pela amostra 1204, que está claramente individualizada do resto das produções que se presumem serem originárias do estuário do Tejo (fig. 6). Esta produção é caracterizada por conter os maiores valores de $\mathrm{Fe}_{2} \mathrm{O}_{3}$ (38256) e $\mathrm{CaO}$ (66759) e valores médios de $\mathrm{K}_{2} \mathrm{O}$ (24071) e $\mathrm{MnO}$ (199), contendo os menores de $\mathrm{TiO}_{2}$ (4330). Por outro lado, essas diferenças observadas nos componentes maioritários também foram observadas nas razões composicionais minoritárias, sendo sua ordem: $\mathrm{Sr}$ (193), V (124), Zn (119), Rb (116), Cr (89), Zr (85.05), $\mathrm{Cu}$ (23), As (11), Th (10), Pb (9) e Mo (7). Finalmente, esta amostra não contém urânio. Cabe, contudo, adiantar desde já que esta peça foi classificada de acordo com o tipo 10.1.1.1 de Ramon Torres (1995), e que as suas características macroscópicas indicam uma origem alóctone, muito provavelmente da região mais meridional da Península Ibérica. Este elemento permite, por um lado, corroborar as propostas de definição dos fabricos anteriormente esboçada, uma vez que mostra uma clara diferenciação na composição das produções taganas e outras que parecem ser claramente oriundas do sul peninsular. A superfície desta ânfora não teria nenhum

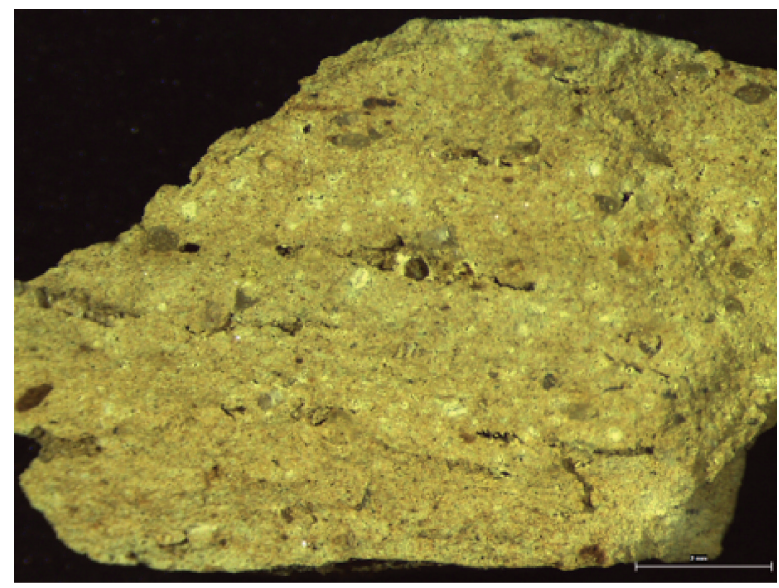

Figura 6. Ânfora n. ${ }^{\circ} 1204$ do Porto de Sabugueiro, classificada como uma provável produção da área de Málaga atribuída ao tipo 10.1.1.1. de Ramon Torres.

tratamento específico, ou pelo menos este não pôde ser identificado; a existir, tratar-se-ia de uma aguada feita com base ao recurso das mesmas matérias-primas. As tonalidades de sua matriz são caracterizadas por seu tom bege que, além disso, denota uma grande homogeneidade durante a cozedura oxidante. Os desengordurantes identificados variam substancialmente em relação aos identificados nos grupos anteriores, sendo o quartzo e os foraminíferos, que ocorrem em valores próximos a $20 \%$ do total das matérias-primas utilizadas. Por outro lado, os desengordurantes possuem uma morfologia arredondada como consequência de factores erosivos, estando orientados paralelamente às paredes. Finalmente, as porosidades identificadas são estrias e poros, que se formam durante a secagem e a cozedura.

\subsubsection{As formas}

Entre os fragmentos que foram integrados no grupo das produções locais/regionais, foi possível reconhecer seis morfologias distintas (tipos 1, 3, 4, 5, 6 e 7), tendo sido utilizada a tabela tipológica proposta para as ânforas do estuário do Tejo (Sousa e Pimenta 2014). A este conjunto somam-se ainda 24 fragmentos de bordo que não foram passíveis de classificação devido ao seu mau estado de conservação.

\subsubsection{Tipo 1}

As ânforas do tipo 1 do estuário do Tejo correspondem a produções regionais inspiradas nos protótipos do Sul 


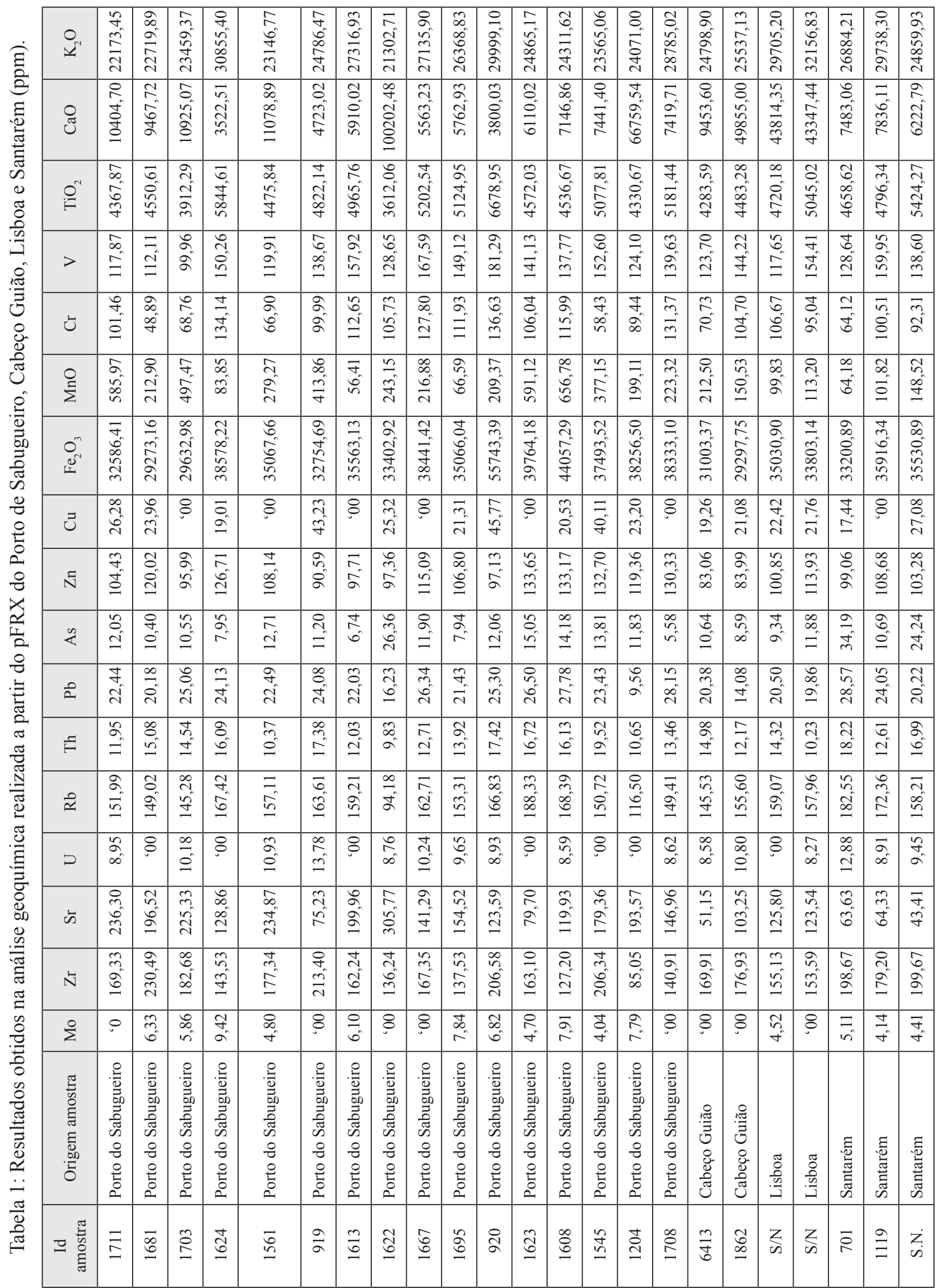


Peninsular integrados, grosso modo, nos tipos 10.1.1.1 e 10.1.2.1 da tipologia elaborada por J. Ramon Torres (1995).

A origem desta produção deverá relacionar-se directamente com a instalação, no estuário do Tejo, de oleiros provenientes do sul da Península Ibérica durante os finais do século VIII / inícios do século VII a.n.e., em cronologia tradicional, e que reproduziram os modelos em uso nas áreas mais meridionais. Os centros produtores fundados por esses oleiros que se estabelecem na área centro atlântica irão desenvolver certas especificidades regionais no quadro dos contentores anfóricos, que devem ser entendidas como evoluções paralelas a outras documentadas nos restantes espaços peninsulares. No caso concreto das produções taganas, o aspecto que mais se destaca é a maior amplitude de bordo (geralmente entre os 16 e os $19 \mathrm{~cm}$ ), quando comparadas com as morfologias mais meridionais, ainda que outras alterações ao nível dos bordos sejam também identificáveis. No que diz respeito às características gerais destes recipientes, e apesar da semelhança de alguns exemplares com os protótipos 10.1.1.1 e 10.1.2.1 de Ramon Torres, pensamos ser mais adequado estabelecer a sua classificação com base na tipologia estabelecida para a região. Ainda assim, é necessário indicar que recentes publicações (Olaio 2018, Sousa e Guerra 2018) têm vindo a evidenciar uma acentuada variabilidade morfológica no âmbito deste tipo 1 do estuário do Tejo, que justifica uma futura reelaboração e sub-divisão das tabelas tipológicas existentes. Esta tarefa terá de ser, contudo, suportada por dados contextuais concretos que permitam identificar momentos mais exactos do aparecimento de algumas destas variantes, condições que que até à data ainda não se verificaram.

No que diz respeito à cronologia deste tipo 1 do estuário do Tejo, o início da produção parece situar-se em momentos relativamente antigos, de acordo com os vestígios recolhidos nos contextos inferiores da Rua de São Mamede ao Caldas, datados em torno a finais do séc. VIII / inícios do séc. VII a.n.e. (Pimenta et al. 2014b, Sousa e Pimenta 2014). Contudo, os dados existentes parecem indicar uma longa diacronia da sua utilização. Na Rua dos Correeiros, estas ânforas surgem em contextos datados entre o século $\mathrm{V}$ a.n.e. e os inícios da centúria seguinte, o que indicava já uma utilização recorrente durante os meados do $1^{\circ}$ milénio (Sousa 2014). Estudos mais recentes, concretamente os efectuados sobre os conjuntos artefactuais do Cabeço Guião, na zona do Cartaxo, evidenciaram ainda a utilização desta morfologia em momentos mais avançados do século IV e III a.n.e. (Arruda et al. 2017).
Sobre os centros de produção, desconhecem-se, até ao momento, dados concretos que permitam discriminar origens mais específicas dentro da escala regional, uma situação que é estendível a todos os tipos taganos. Contudo, e para o caso específico do tipo 1, cabe referir a identificação de alguns destes fragmentos deformados no sítio da Quinta da Marquesa, em Vila Franca de Xira, estando associados a prismas cerâmicos, o que pode indiciar uma área de produção neste local (Pimenta e Mendes 2011: 603-607).

Dentro do conjunto anfórico do Porto do Sabugueiro, foram identificados 17 fragmentos de bordo integráveis no tipo 1 do estuário do Tejo, distribuídos pelos grupos de fabrico I-A (oito exemplares), I-B (sete exemplares), III (um exemplar) e IV (um exemplar). Os recipientes desta morfologia correspondem a 7\% do conjunto (fig. 7).

Em termos formais, e como já foi referido anteriormente, trata-se de um grupo bastante heterogéneo. Exemplares com diâmetros reduzidos e perfis muito aproximados do tipo 10.1.2.1 de Ramon Torres (n. ${ }^{\circ} 1207$ e 1206) convivem com fragmentos de diâmetro consideravelmente mais amplo, que por vezes apresentam o bordo mais evertido e arredondado (n. ${ }^{\circ} 1721,1720,1715$ e 1205,1523$)$, características que devem ser associadas ao desenvolvimento interno destas produções regionais. Infelizmente, a inexistência de dados contextuais no Porto do Sabugueiro impossibilita esboçar qualquer leitura sobre a evolução destas especificidades.

Cabe ainda referir a presença de cinco exemplares pertencentes aos grupos de fabrico I-A (n. ${ }^{\circ} 839$ e 775), I-B (n. $\left.{ }^{\circ} 1215\right)$ e IV (n. ${ }^{\circ} 1520$ e S.N.a) que parecem corresponder a formas já de transição entre o tipo 1 e o 3 (fig. 7), cujas morfologias surgem, nas sequências estratigráficas de Lisboa, a partir do séc. VI a.n.e. (Sousa e Guerra 2018: 69 e 73). Estas formas de transição correspondem a $2 \%$ da totalidade do conjunto.

\subsubsection{Tipo 3}

O tipo 3 do estuário do Tejo caracteriza-se por apresentar um corpo mais ovalado, um colo curto e um bordo claramente diferenciado externamente, sendo a sua secção variável (Sousa e Pimenta 2014).

Trata-se de uma morfologia que surge, em Lisboa, em contextos da segunda metade do século VI a.n.e. (Sousa e Pimenta 2014), o que foi recentemente corroborado pela estratigrafia do Largo de Santa Cruz do Castelo (Sousa e Guerra 2018). Sobre a sua origem, cabe referir que as semelhanças que este tipo apresenta 
com outras morfologias contemporâneas meridionais (tipo Pellicer B/C - Pellicer Catalán 1978) e das zonas mais interiores do território peninsular (tipos Cancho Roano I e II - Guerrero Ayuso 1991), poderá efectivamente indicar algumas influências exógenas nas produções regionais do estuário do Tejo. Contudo, o peso da própria evolução interna dos recipientes anfóricos terá sido, em nossa opinião, o factor determinante na emergência deste tipo 3, considerando, sobretudo, que as características que o definem parecem surgir ainda durante a primeira metade do século VI a.n.e. (Sousa e Guerra 2018: 69), sendo, portanto, anteriores às dos casos referidos.

A utilização destes recipientes durante as fases mais tardias da Idade do Ferro foi recorrente, mas os dados existentes indicam que este tipo desaparece dos repertórios artefactuais num momento anterior à segunda metade do século II a.n.e. (Sousa e Pimenta 2014: 308).

A forma está bem documentada não só em Lisboa, mas também nos sítios da Idade do Ferro identificados nos concelhos de Almada (Olaio 2018), Amadora, Sintra (Sousa 2014), Oeiras (Cardoso et al. 2014, Cardoso e Silva 2013), Cascais (Cardoso 1991, Cardoso e Encarnação 2013), Almeirim (Sousa et al. 2017, Pimenta et al. 2018), Alpiarça (Arruda et al. 2014), Cartaxo (Arruda et al. 2017) e Santarém (Arruda 2000, Diogo 1993).

No Porto do Sabugueiro, o tipo 3 do estuário do Tejo está representado por 16 exemplares, integráveis nos grupos de fabrico I-A (cinco exemplares), I-B (quatro exemplares), II (quatro exemplares), III (um exemplar) e IV (dois exemplares). Correspondem a 7\% da totalidade do conjunto (fig. 7 e 8).

Em termos morfológicos, deve referir-se que dois exemplares $\left(n .^{\circ} 1203,1525\right)$ apresentam a parte superior do bordo muito evertida, o que poderia talvez indicar alguma antiguidade, uma vez que parece estar em linha de continuidade com as produções do tipo 1 do estuário do Tejo. Os restantes fragmentos enquadram-se já nas morfologias mais clássicas definidas para este tipo (Sousa e Pimenta 2014).

\subsubsection{Tipo 4}

O tipo 4 do estuário do Tejo é distinguível sobretudo pelas características do bordo, que é alto e vertical, externamente, e engrossado internamente.

Trata-se de uma morfologia que surge nos repertórios artefactuais regionais a partir do século $\mathrm{V}$ a.n.e., não parecendo, tal como no caso anterior, atingir a época romana (Sousa e Pimenta 2014).
O tipo está relativamente bem representado em todo o estuário do Tejo, concretamente em Lisboa (Sousa 2014), Almada (Barros e Soares 2004, Olaio 2018). Amadora, Sintra (Sousa 2014), Oeiras (Cardoso e Silva 2013, Cardoso et al. 2014), Cascais (Cardoso e Encarnação 2013), Almeirim (Sousa et al. 2017, Pimenta et al. 2018), Alpiarça (Arruda et al. 2014) e Cartaxo (Arruda et al. 2017).

Entre o conjunto anfórico recolhido no Porto do Sabugueiro, este tipo está documentado através de apenas seis exemplares (n. ${ }^{\circ} 1725,1281,1212,1727,1623$ e S.N. b), que correspondem a $3 \%$ do conjunto (fig. 8), e que se integram nos grupos de fabrico I-A (três exemplares), III (dois exemplares) e IV (um exemplar). Esta escassez quantitativa é, aliás, comum à maioria dos sítios localizados nas áreas mais próximas, com a excepção do Cabeço Guião (Arruda et al. 2017).

Deve, contudo, referir-se que um dos exemplares é um pouco atípico no que diz respeito à forma (n. $\left.{ }^{\circ} 1623\right)$, situação que se pode explicar pelo facto de pertencer ao grupo de fabrico III, para o qual se assume uma origem mais interior, sendo os exemplares que serviram para a seriação tipológica produções da área de Lisboa/Almaraz. Poderá, assim, corresponder apenas a uma pequena variação dos centros de produção do curso superior do estuário.

\subsubsection{Tipo 5}

O tipo 5 incorpora recipientes de corpo mais ovoide, sendo o bordo reentrante e espessado, com secção geralmente ovalada. $\mathrm{Na}$ tipologia estabelecida para as produções anfóricas taganas, esta forma foi definida exclusivamente com base nos fragmentos do Porto do Sabugueiro (Sousa e Pimenta 2014: 308) e, até ao momento, não se encontra documentada em nenhum outro local.

Os materiais recuperados no sítio de Muge permitiram (fig. 8 a 10), inclusivamente, apresentar uma proposta de reconstituição mais completa desta morfologia, tendo sido possível associar asas de secção oval com sulcos na área externa e fundos de perfil cónico (n. ${ }^{\circ} 1800$ - Pimenta e Mendes 2008, Sousa e Pimenta 2014).

Com efeito, grande parte dos exemplares classificados como tipo 5 apresentam fabricos que indicam uma possível origem local (grupos de fabrico II - 34 fragmentos; III - 31 fragmentos; fabrico raro A - um fragmento), sendo estes fabricos muito raros na própria zona estuarina. Pastas semelhantes foram apenas documentadas na margem oposta, no Cabeço 


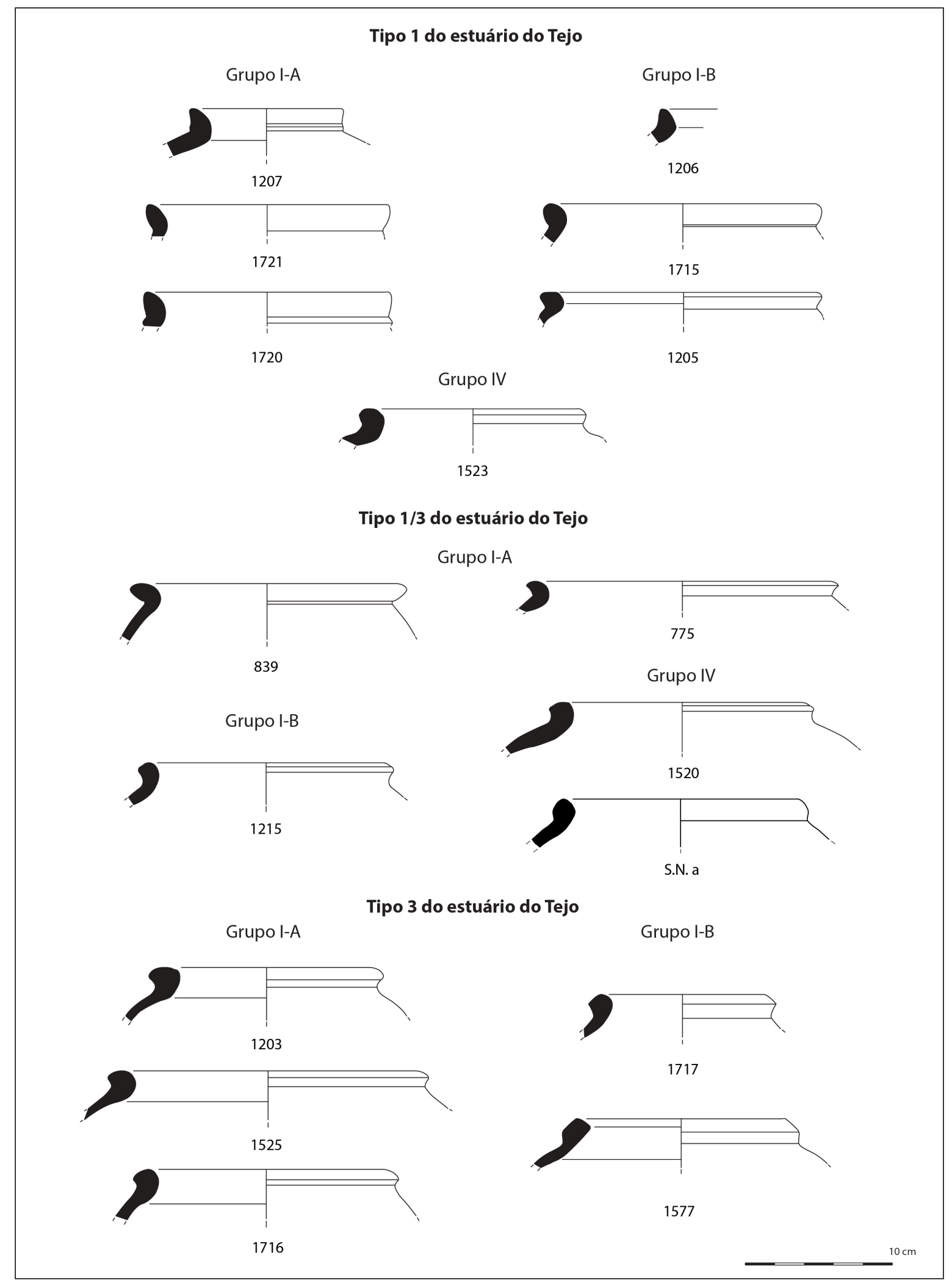

Figura 7. Ânforas dos tipos 1, 1/3 e 3 do estuário do Tejo. 
Guião, mas correspondem a escassos fragmentos (Arruda et al. 2017: 352). Contudo, deve ainda salientar-se a representatividade de recipientes que se incluem no grupo de fabrico IV (22 fragmentos), para o qual se assume uma proveniência um pouco mais meridional dentro da zona estuarina. Este é um dado importante considerando que até ao momento não se equacionava a possibilidade de este tipo formal poder ser também fabricado em zonas mais meridionais.

Considerando a escassez de dados contextuais, é muito difícil estabelecer parâmetros cronológicos para esta forma, ainda que se admita poder ser bastante tardia no quadro da Idade do Ferro (Sousa e Pimenta 2014: 308), e de poder eventualmente transitar para o período seguinte, ainda que tal proposta careça de dados concretos que a corroborem.

Como já foi indicado, esta morfologia é abundante no conjunto de ânforas recolhido no Porto do Sabugueiro, contando com 88 exemplares, que correspondem a $38 \%$ do conjunto.

Os bordos são muito variáveis no que diz respeito à sua secção, podendo apresentar sulcos pouco acentuados na parede externa (n. ${ }^{\circ} 1658,1586,1552,1675$, $1619,1553)$, apesar de genericamente todos apresentarem formato ovalado. Os diâmetros são também bastante diversos, podendo oscilar entre os oito e os quinze centímetros.

\subsubsection{Tipo 6}

O tipo 6 do estuário do Tejo foi individualizado, essencialmente, por apresentar bordos curtos, reentrantes e espessados, e ombros de tendência horizontal (Sousa e Pimenta 2014).

Trata-se de um tipo relativamente tardio no quadro das produções taganas. Ainda que os exemplares mais antigos tenham sido documentados na Rua dos Correeiros, cuja cronologia está centrada entre o século V e os inícios do século IV a.n.e. (Sousa 2014, Sousa e Pimenta 2014), estes parecem corresponder a protótipos antigos desta morfologia, que se desenvolveram posteriormente para formas com ombros mais horizontais. De qualquer forma, o tipo permanece seguramente nos quadros artefactuais até aos inícios do período romano-republicano (Pimenta et al. 2005, Sousa e Pimenta 2014). Encontra-se bem documentado em Lisboa, Almada (Cardoso e Carreira 1997-1998), Amadora (Sousa 2014), Cascais (Cardoso e Encarnação 2013) e, mais no interior do estuário, também em Castanheira do Ribatejo (Pimenta et al. 2010), Quinta do Bulhaco II (Pimenta e Mendes 2015), Cabeço Guião (Arruda et al 2017), Eira da Alorna (Pimenta et al. 2018), Alto dos Cacos (Sousa et al. 2017), Alto do Castelo (Arruda et al. 2014) e na Alcáçova de Santarém (Arruda 2000).

Tal como a forma anterior, é um dos tipos mais bem representados no conjunto do Porto do Sabugueiro, contando com 57 exemplares (fig. 10 e 11), que se distribuem pelos fabricos I-B (um fragmento), II (17 fragmentos), III (21 fragmentos) e IV (18 fragmentos).

No conjunto, este tipo 6 corresponde a $25 \%$ do conjunto analisado.

Os bordos apresentam perfis bastante variáveis, uma diversidade que poderá justificar, futuramente, uma ulterior subdivisão desta morfologia, ainda que tal processo só possa ser estabelecido com base em dados contextuais precisos e em perfis mais completos, que não estão ainda disponíveis. Mesmo assim, torna-se clara a existência de bordos com um acentuado espessamento interno, espessamento que em outros casos é também externo.

\subsubsection{Tipo 7}

O tipo 7 do estuário do Tejo engloba recipientes cuja parte superior é troncocónica, sendo as paredes de tendência rectilínea e o bordo espessado interiormente.

A sua cronologia é difícil de estabelecer com precisão devido à escassez de dados contextuais. Ainda assim, cabe referir a identificação deste tipo no Cabeço Guião, ocupado entre o século IV e III a.n.e. (Arruda et al. 2017), no Castelo de São Jorge, em níveis do século III a.n.e., e nos níveis pré-romanos de Chibanes (Silva e Soares 2012), o que indica tratar-se de uma forma tardia no quadro das produções anfóricas taganas, que se mantém contudo em utilização até ao período romano-republicano (Sousa e Pimenta 2014). Com efeito, a sua presença em contextos do último terço do século II a.n.e. está bem documentada na área urbana de Lisboa (Pimenta 2005, Pimenta et al. 2014c). Esta forma foi ainda identificada nos concelhos de Cascais (Nieuwendam e Santos 2008), Almada (Olaio 2018) e Vila Franca de Xira (Pimenta e Mendes 2011, 2015).

No Porto do Sabugueiro, foram recolhidos 14 exemplares integráveis nesta forma, que correspondem a $6 \%$ do conjunto (fig. 11). Distribuem-se pelos grupos de fabrico I-A (dois fragmentos), I-B (quatro fragmentos), II (dois fragmentos), III (dois fragmentos) e IV (três fragmentos). A secção interna do bordo é geralmente sub-triangular, apresentando por vezes um pequeno sulco na zona interna do bordo (n. ${ }^{\circ} 1644,1729$, 1723, 1531), mais ou menos acentuado, e que recorda, 


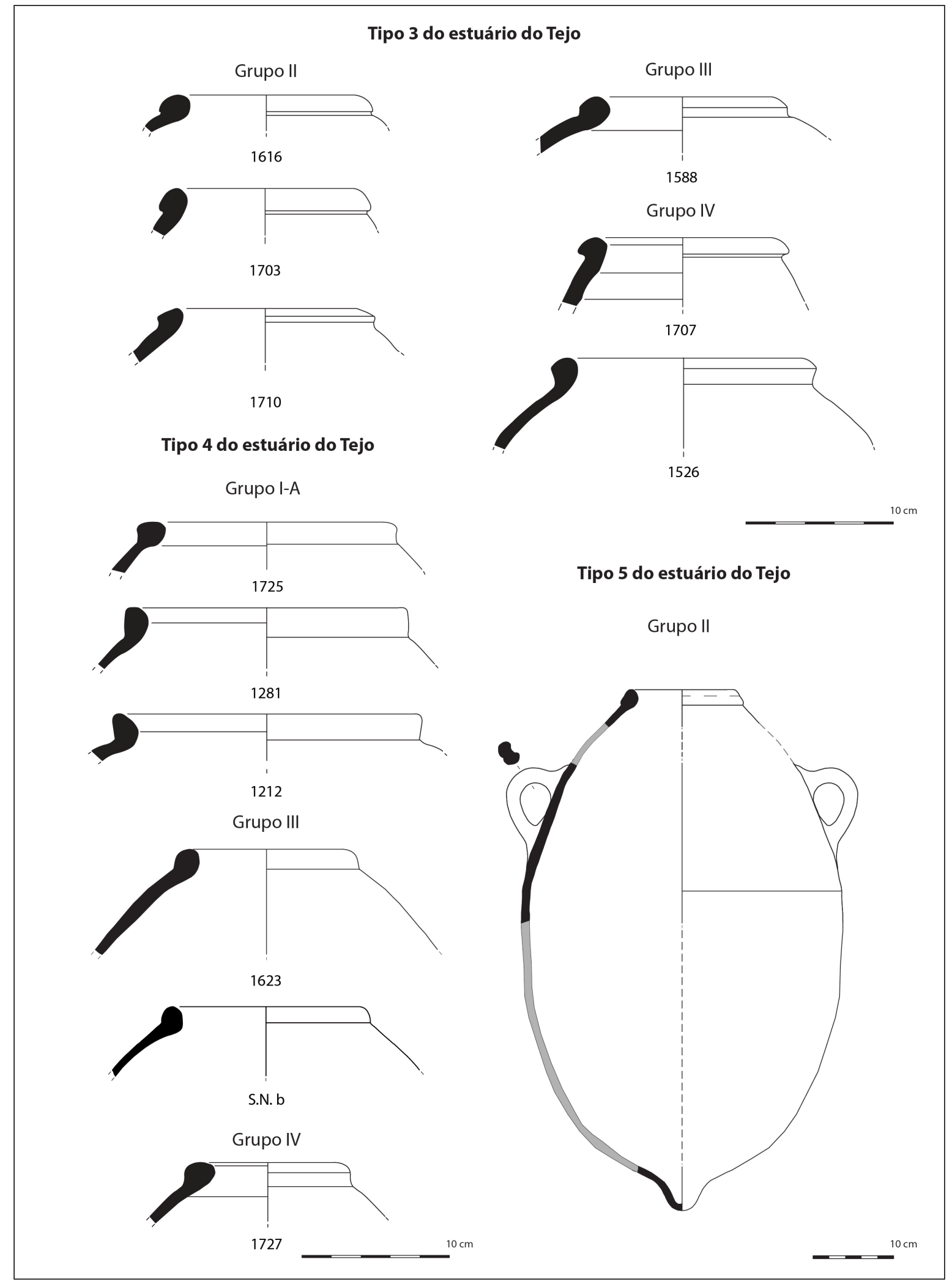

Figura 8. Ânforas dos tipos 3, 4 e 5 do estuário do Tejo. 
de certa forma, as características de algumas ânforas da área da Campina Gaditana do tipo 8.1.1.2. (Ramon Torres 1995; Carretero Poblete 2004).

\subsubsection{Formas de difícil classificação}

Dentro das produções locais/regionais, cabe ainda referir quatro fragmentos de bordo que não permitiram uma classificação precisa (fig. 12). Todos eles se integram nos fabricos que consideramos serem originários das áreas mais interiores do estuário (grupo II - um fragmento; III - um fragmento), e de outra zona mais difícil de determinar (grupo IV - dois fragmentos), situação que pode justificar algumas das particularidades morfológicas.

Um destes fragmentos (n. $\left.{ }^{\circ} 1672\right)$ poderia eventualmente aproximar-se do tipo 1 do estuário do Tejo, ainda que tenha uma secção mais circular e um bordo de tendência mais vertical do que os exemplares que normalmente são integrados neste tipo.

Dois fragmentos (n. ${ }^{\circ} 1612$ e 1713) aproximam-se, por sua vez, tanto do tipo 3 , pelas características do bordo, como do tipo 6, pela horizontalidade do ombro, sendo, portanto, difícil atribuir-lhes uma classificação específica.

O último fragmento de bordo, muito mal conservado, parece exibir um bordo de tendência vertical, que poderia aparentar-se, ainda que com reservas, com o tipo 7 (n. $\left.{ }^{\circ} 1646\right)$.

Resta referir ainda a recolha de dezenas de fragmentos de asas pertencentes aos vários fabricos definidos, que exibem secções circulares e, em alguns casos, ovais com sulco na zona exterior, e alguns fundos de perfil cónico (fig. 13).

\subsection{Os materiais importados}

Dentro do conjunto recolhido no Porto do Sabugueiro foi ainda possível identificar nove fragmentos de ânforas (fig. 12) que, pelas suas características de fabrico, parecem corresponder a importações das regiões meridionais da Península Ibérica, concretamente da Andaluzia.

Dois destes exemplares (n. ${ }^{\circ} 1211$ e 1204) apresentam fabricos que são geralmente associados à área de Málaga. A morfologia do bordo e o ressalto que apresenta no lábio, na junção à parede, permitem uma classificação no tipo 10.1.1.1 de Ramon Torres, ainda que se deva assumir que a distinção entre este e a forma que lhe sucede (tipo 10.1.2.1) nem sempre seja fácil de estabelecer com precisão.
No conjunto do Porto do Sabugueiro, surgem também cinco fragmentos que parecem corresponder a ânforas do tipo Pellicer B/C (n. ${ }^{\circ} 1736,1730,1734$, 1735, 1733), algumas das quais já publicadas (García Fernández 2019: 137 - P.SAB-08-3185 = n. ${ }^{\circ}$ 1733; P. SAB-08-0989 = n. ${ }^{\circ}$ 1734; P.SAB-08-0301 = n. ${ }^{\circ} 1736$; P.SAB-08-3211 = n. ${ }^{\circ}$ 1735), ainda que um destes (n. ${ }^{\circ}$ 1734) apresente a zona interna mais engrossada, o que poderia permitir uma aproximação ao tipo Pellicer D. As suas pastas alaranjadas (por vezes com núcleos acinzentados), compactas e relativamente bem depuradas, indicam uma origem no Baixo Guadalquivir. Deve ainda referir-se que as duas outras ânforas consideradas como possíveis importações (García Fernández 2019) foram, após a análise integral do conjunto, consideradas como pertencentes aos grupos II e IV (2019: 137 - P.SAB-08-0161 = n. ${ }^{\circ} 1703$ do tipo 3 do estuário do Tejo; P.SAB-08-0046 = n. ${ }^{\circ} 1622$ do tipo 5 do estuário do Tejo).

Um outro fragmento, cujo bordo é pouco diferenciado e de tendência mais horizontal, sendo ainda espessado internamente, poderá eventualmente corresponder a uma ânfora do tipo Pellicer D (n. ${ }^{\circ}$ 1651). As características da sua pasta são muito semelhantes às anteriores, sugerindo, igualmente, uma origem do Baixo Guadalquivir, ainda que esta proposta seja feita com algumas reservas, sendo necessário corroborá-la com análises arqueométricas futuras.

Uma situação muito similar aplica-se também ao último fragmento que consideramos ser de importação (n. ${ }^{\circ}$ 1647). As características da sua pasta e mesmo a sua morfologia permitem uma aproximação às produções da Campiña Gaditana do tipo 8.1.1.2 de Ramon Torres (Ramon Torres 1995; Carretero Poblete 2004), ainda que esta associação tenha sido feita também com reservas.

\section{DISCUSSÃO E CONCLUSÃO}

O conjunto de ânforas da Idade do Ferro e de tradição pré-romana recuperado no Porto do Sabugueiro é um dos mais representativos do estuário do Tejo, contando com mais de duas centenas de fragmentos de bordo (tab. 2). A diversidade morfológica e a variedade de fabricos documentados estão seguramente relacionadas com a longa diacronia de ocupação do sítio durante o $1^{\mathrm{o}}$ milénio a.n.e., sendo de lamentar que as prolongadas e intensivas práticas agrícolas tenham impossibilitado conjugar este estudo com dados estratigráficos e contextuais mais precisos. 


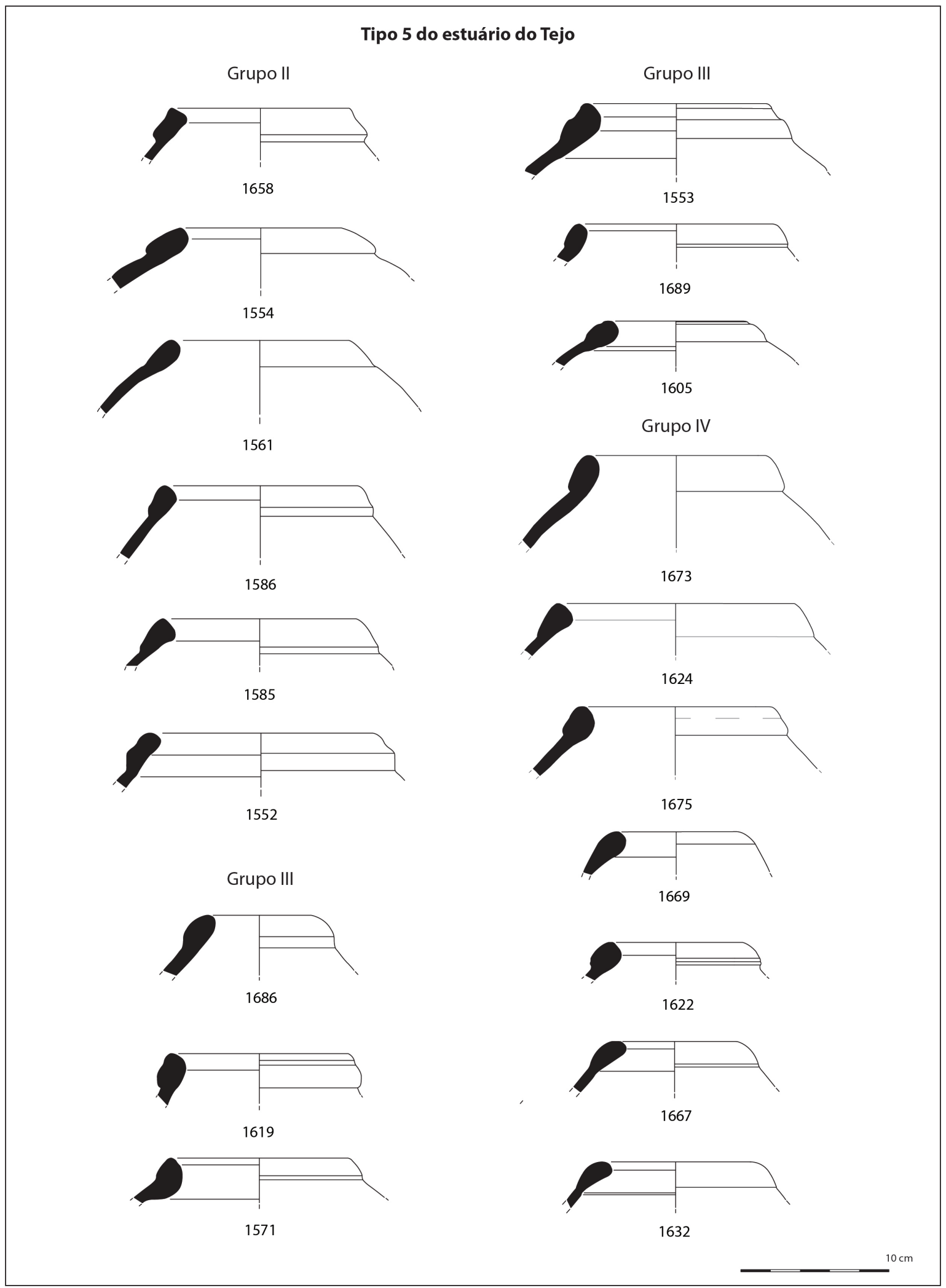

Figura 9. Ânforas do tipo 5 do estuário do Tejo. 


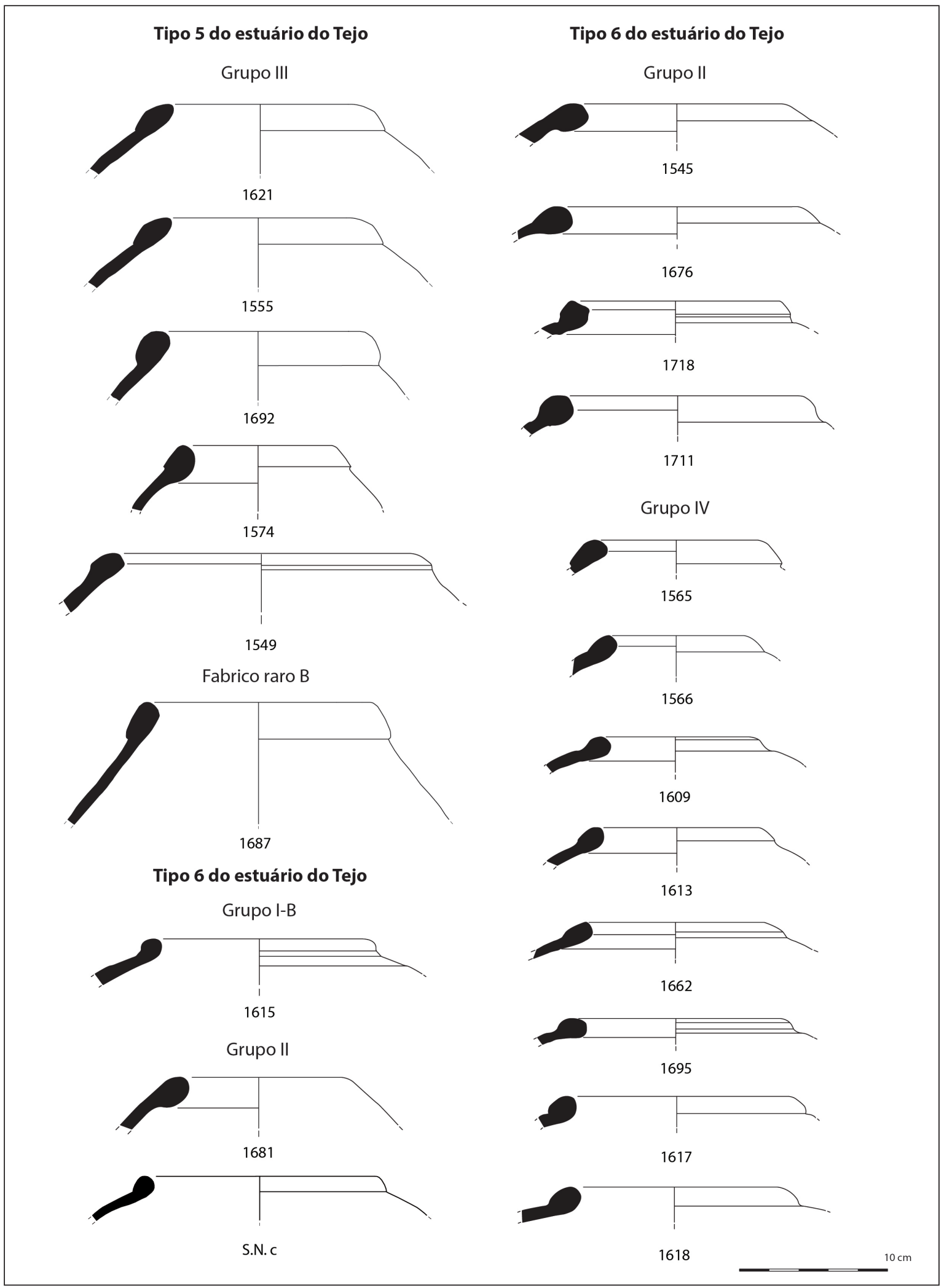

Figura 10. Ânforas dos tipos 5 e 6 do estuário do Tejo. 
O grupo das produções locais e regionais (grupos de fabrico I, II, III, IV e fabrico raro A e B) é, sem qualquer dúvida, o mais representativo, correspondendo a $96 \%$ do conjunto, enquanto que os materiais de provável importação correspondem a apenas $4 \%$, sendo esta escassa expressão recorrente no quadro dos conjuntos artefactuais regionais (Sousa 2014, 2017).

Dentro ainda das produções taganas (fig. 14 e 15), a única morfologia ausente é o tipo 2 do estuário do Tejo (Sousa e Pimenta 2014), sendo, contudo, de referir que a forma é também rara em outros sítios localizados nas áreas mais interiores do estuário. Os restantes tipos estão todos relativamente bem representados.

O tipo 1, cronologicamente mais antigo, mas que se prolonga até momentos bem avançados do $1^{\circ} \mathrm{mi}-$ lénio a.n.e., como já foi anteriormente referido, constitui $7 \%$ do conjunto (17 fragmentos), podendo acrescentar-se ainda as formas de transição $1 / 3$, que correspondem a outros $2 \%$ (cinco fragmentos). Estas morfologias englobam recipientes produzidos, sobretudo, na foz do estuário, mais especificamente na área de Lisboa/Almaraz, integrados no grupo de fabrico I (18 fragmentos). O grupo de fabrico IV, que poderá localizar-se nas suas proximidades, conta com três fragmentos, e as pastas mais típicas do curso interior do estuário (grupo III) contam com apenas um exemplar.

O tipo 3, recorrente nas produções regionais a partir da segunda metade do século VI a.n.e., conta com 7\% do conjunto total (16 fragmentos). Neste caso, encontramos um maior equilíbrio entre as produções da foz (nove exemplares), "intermédias" (dois exemplares) e as do interior (cinco exemplares), o que poderá talvez indicar que o início do fabrico de ânforas nas áreas mais interiores do estuário poderá ter ocorrido apenas a partir da segunda metade do século a.n.e..

A forma menos bem representada é o tipo 4, característico da segunda metade do $1^{\circ}$ milénio a.n.e., com apenas 3\% (seis exemplares), notando-se uma maioria dos fabricos da foz (três exemplares) e uma certa simetria entre os fabricos "intermédios" (um exemplar) e da zona interior (um exemplar).

A mesma situação verifica-se no tipo 7, mais tardio, que conta com $6 \%$ (14 exemplares - dos quais seis terão sido produzidos na zona da foz e cinco na área mais interior, sendo três da zona "intermédia").

As formas dominantes são, sem qualquer dúvida, os tipos 5 e 6 , que constituem, respectivamente, $38 \%$ (88 exemplares) e $25 \%$ (57 exemplares) do conjunto. A grande maioria destas peças são pertencentes aos fabricos que assumimos serem do próprio Porto do
Sabugueiro ou de uma área muito próxima (103 fragmentos dos grupos II e III). Apenas um, da forma 6, é passível de ser integrado nas produções típicas da zona de Lisboa/Almaraz (grupo I), sendo os restantes do grupo IV, para o qual se assume uma origem próxima da anterior (40 fragmentos).

A expressividade destas produções locais no Porto do Sabugueiro foi já associada à possibilidade de o local ter constituído, durante os momentos mais tardios do $1^{\circ}$ milénio, um centro de produção de contentores anfóricos (Sousa e Pimenta 2014), provavelmente relacionado com a proximidade de locais vocacionados para a exploração agrícola, como é o caso do Cabeço Guião, ocupado durante o século IV e III a.n.e. (Arruda et al. 2017), e localizado exactamente em frente do Porto do Sabugueiro, na margem oposta do Tejo (Sousa 2017). Contudo, não podemos deixar de estranhar a escassez, nesse mesmo local, de fragmentos que partilhem as características de fabrico desta zona mais interior, assim como a ausência de ânforas que sejam claramente integráveis no tipo 5 (Arruda et al. 2017), que são tão abundantes no Porto do Sabugueiro.

Esta estranha situação poderia eventualmente explicar-se de duas formas.

Por um lado, poderia equacionar-se que o Porto do Sabugueiro fosse, durante a Idade do Ferro, um núcleo de primeira importância, capaz de reunir e concentrar os excedentes agrícolas do território imediato, envazando-os directamente em contentores de produção local que seriam depois distribuídos para outras áreas. Esta relação de tipo unidirecional poderia, assim, justificar a escassez desses mesmos recipientes nos sítios de vocação agrícola das proximidades, que seriam, por sua vez, abastecidos sobretudo por outros produtos com origem na zona mais meridional do estuário. Esta hipótese enfrenta, contudo, um sério obstáculo, que é justamente a escassez destes fabricos anfóricos mais interiores em outras áreas do estuário do Tejo, apesar dessa carência poder ser imputada a problemas de identificação dos mesmos. Contudo, a verdade é que entre os vários conjuntos artefactuais que temos vindo a publicar (Arruda et al. 2014, 2017, 2018, Cardoso et al. 2014, Sousa 2014, Sousa e Arruda 2018, Sousa e Guerra 2018, Sousa et al. 2017, Pimenta et al. 2018) as produções da área da foz, Lisboa/Almaraz, parecem ser sempre largamente maioritárias. Ainda assim, parece importante referir que os estudos sobre os fabricos do estuário do Tejo se encontram ainda numa fase preliminar, sendo necessário corroborar estas propostas de proveniência com a 


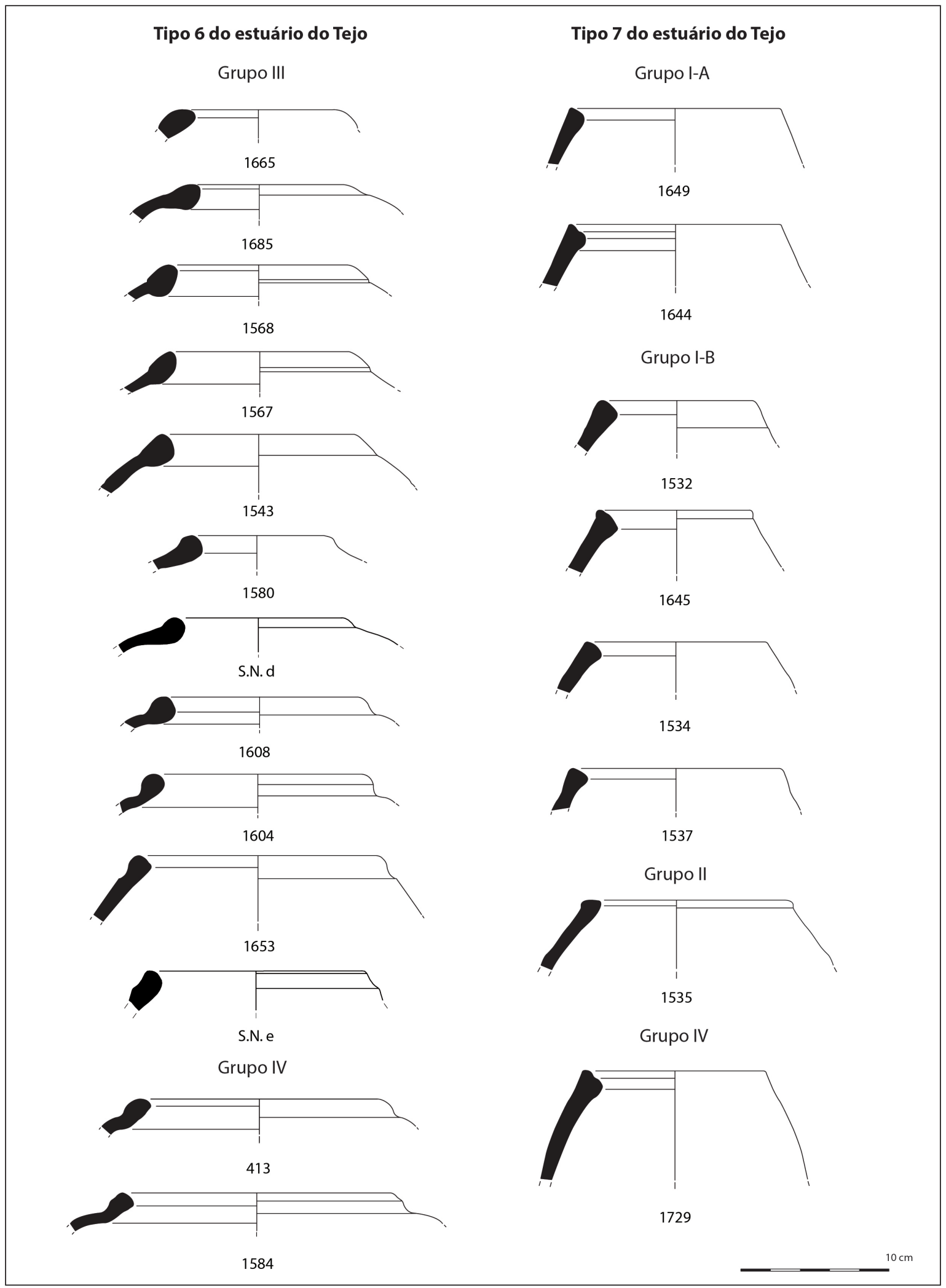

Figura 11. Ânforas dos tipos 6 e 7 do estuário do Tejo. 


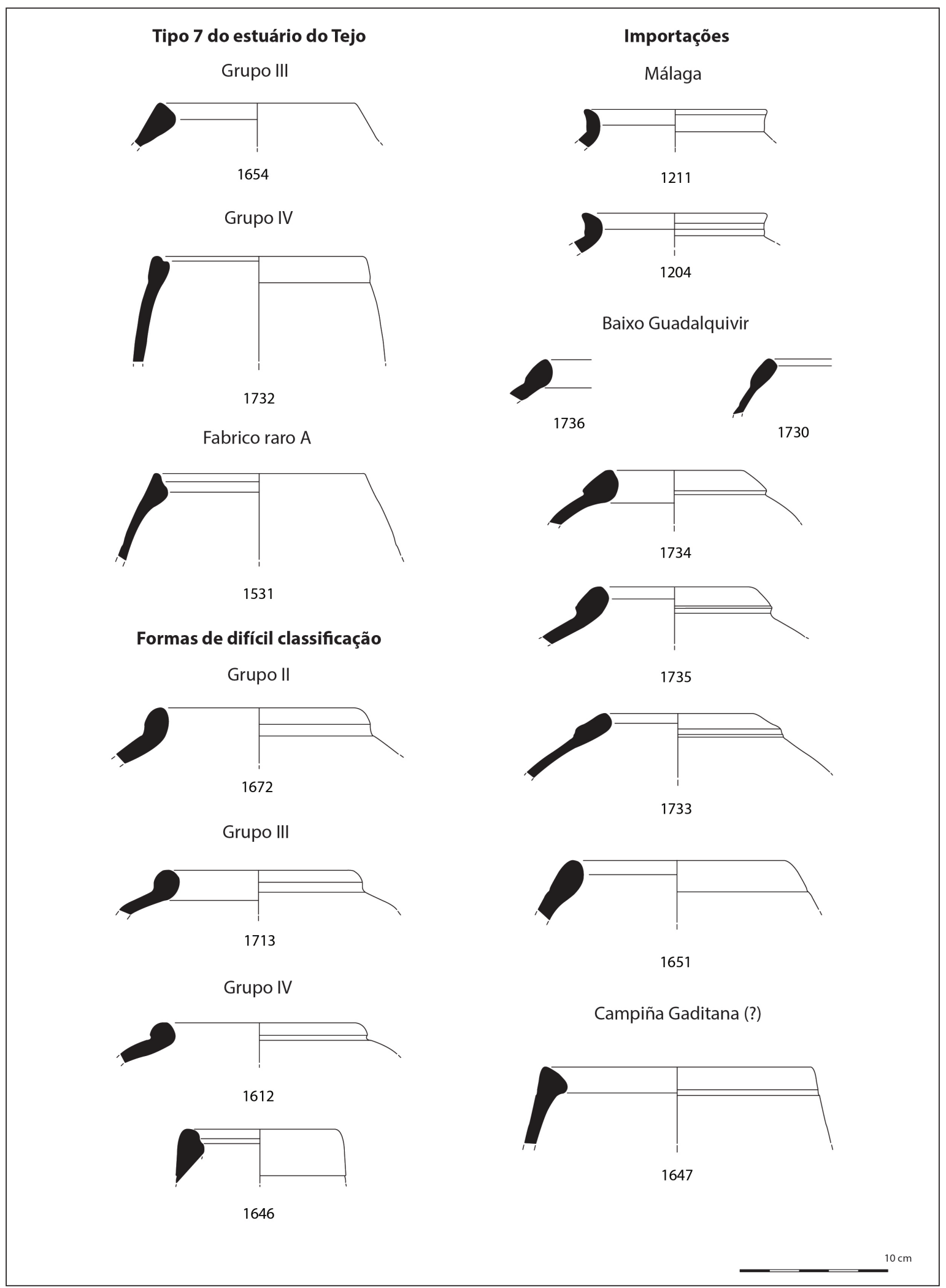

Figura 12. Ânforas dos tipos 7 do estuário do Tejo, formas de difícil classificação e importações. 
Tabela 2: Quantificação das produções locais e regionais do Porto do Sabugueiro de acordo com o grupo de fabrico e forma.

\begin{tabular}{|l|c|c|r|r|r|r|r|c|r|r|}
\hline Fabrico/forma & 1 & \multicolumn{1}{|c|}{$1 / 3$} & \multicolumn{1}{|c|}{3} & 4 & 5 & 6 & 7 & Difícil classificação & Indeterminada & Total \\
\hline Grupo I-A & 8 & 2 & 5 & 3 & - & - & 2 & - & 6 & $\mathbf{2 6}$ \\
\hline Grupo I-B & 7 & 1 & 4 & - & - & 1 & 4 & - & 6 & $\mathbf{2 3}$ \\
\hline Grupo II & - & - & 4 & - & 34 & 17 & 2 & 1 & 3 & $\mathbf{6 1}$ \\
\hline Grupo III & 1 & - & 1 & 2 & 31 & 21 & 2 & 1 & 6 & $\mathbf{6 5}$ \\
\hline Grupo IV & 1 & 2 & 2 & 1 & 22 & 18 & 3 & 2 & 3 & $\mathbf{5 4}$ \\
\hline Fabrico raro A & - & - & - & - & 1 & - & - & - & - & $\mathbf{1}$ \\
\hline Fabrico raro B & - & - & - & - & - & - & 1 & - & - & $\mathbf{1}$ \\
\hline Total & $\mathbf{1 7}$ & $\mathbf{5}$ & $\mathbf{1 6}$ & $\mathbf{6}$ & $\mathbf{8 8}$ & $\mathbf{5 7}$ & $\mathbf{1 4}$ & $\mathbf{4}$ & $\mathbf{2 4}$ & $\mathbf{2 3 1}$ \\
\hline
\end{tabular}

futura identificação de centros de produção e com dados arqueométricos.

Uma segunda possibilidade deve ser, porém, também equacionada. Mesmo não dispondo de informação precisa sobre as cronologias exactas destas produções, alguns dados, sobretudo os tipológicos, permitem admitir que elas poderão corresponder a uma etapa tardia no quadro das produções anfóricas taganas, iniciada num momento muito avançado da Idade do Ferro (talvez a partir do século III a.n.e.) ou mesmo já dentro da fase romano-republicana. Esta cronologia tardia poderia assim justificar a extrema escassez de ânforas produzidas em Porto do Sabugueiro na grande maioria dos sítios pré-romanos do estuário, ocupados sobretudo entre o século V e IV a.C. (Sousa 2017), e a ausência, até ao momento, de ânforas do tipo 5 em todos eles, com a excepção do próprio Porto do Sabugueiro. Só o estudo detalhado de conjuntos artefactuais de fase romano-republicana, que estão ainda por concretizar, poderá responder a esta questão.

Uma outra referência deve ser feita ao número de materiais importados identificados no Porto do Sabugueiro, que, apesar de tudo, é bastante apreciável quando comparado com outros da mesma área geográfica (Sousa 2017), totalizando nove fragmentos.

Destes, dois integram-se seguramente no horizonte cronológico da chamada I Idade do Ferro, concretamente as duas ânforas de provável produção malaguenha do tipo 10.1.1.1 de Ramon Torres (1995), que terão chegado ao Porto do Sabugueiro durante o século VII a.n.e.. Estas importações antigas da Andaluzia não constituem uma novidade no cenário regional, como ficou demonstrado, por exemplo, em Santarém e em Lisboa (Arruda 2000; Pimenta et al. 2014b, Sousa e Guerra 2018).

As ânforas do tipo Pellicer B/C, muito provavelmente produzidas no Baixo Guadalquivir, estão representadas por cinco exemplares. Trata-se de contentores produzidos entre momentos avançados do século VI e o século III a.n.e. (Pellicer Catalán 1978), tendo chegado ao território ocidental atlântico durante este período. Com efeito, e no que diz respeito à importação de produtos alimentares da actual Andaluzia, esta morfologia é, apesar dos reduzidos números que apresenta, a mais frequente na área do Tejo, estando representada, até ao momento, em Lisboa (um exemplar, recolhido em contextos do século V/inícios do IV a.n.e. na Rua dos Correeiros e outros dois na Travessa do Chafariz d'el Rei - Sousa 2014 e García Fernandez 2019) e no Cabeço Guião (um exemplar - Arruda et al. 2017), somando-se agora os cinco do Porto do Sabugueiro. Cabe, contudo, realçar, uma vez mais, esta representatividade do tipo do Guadalquivir neste sítio do curso superior do estuário, que constitui o conjunto mais numeroso destas importações em toda a região.

Deve, contudo, referir-se que, numa publicação recente, F. J. García Fernández (2019) propõe, com base na análise morfológica de algumas peças publicadas, outras possíveis importações destes produtos turdetanos na área do Tejo. Apesar de esta possibilidade ser perfeitamente válida, a grande semelhança que as ânforas do tipo Pellicer B/C apresentam com as produções locais do estuário levam-nos a ter alguma cautela em considerar esses exemplares como importações, até se poder realizar uma análise mais detalhada das respectivas pastas. 


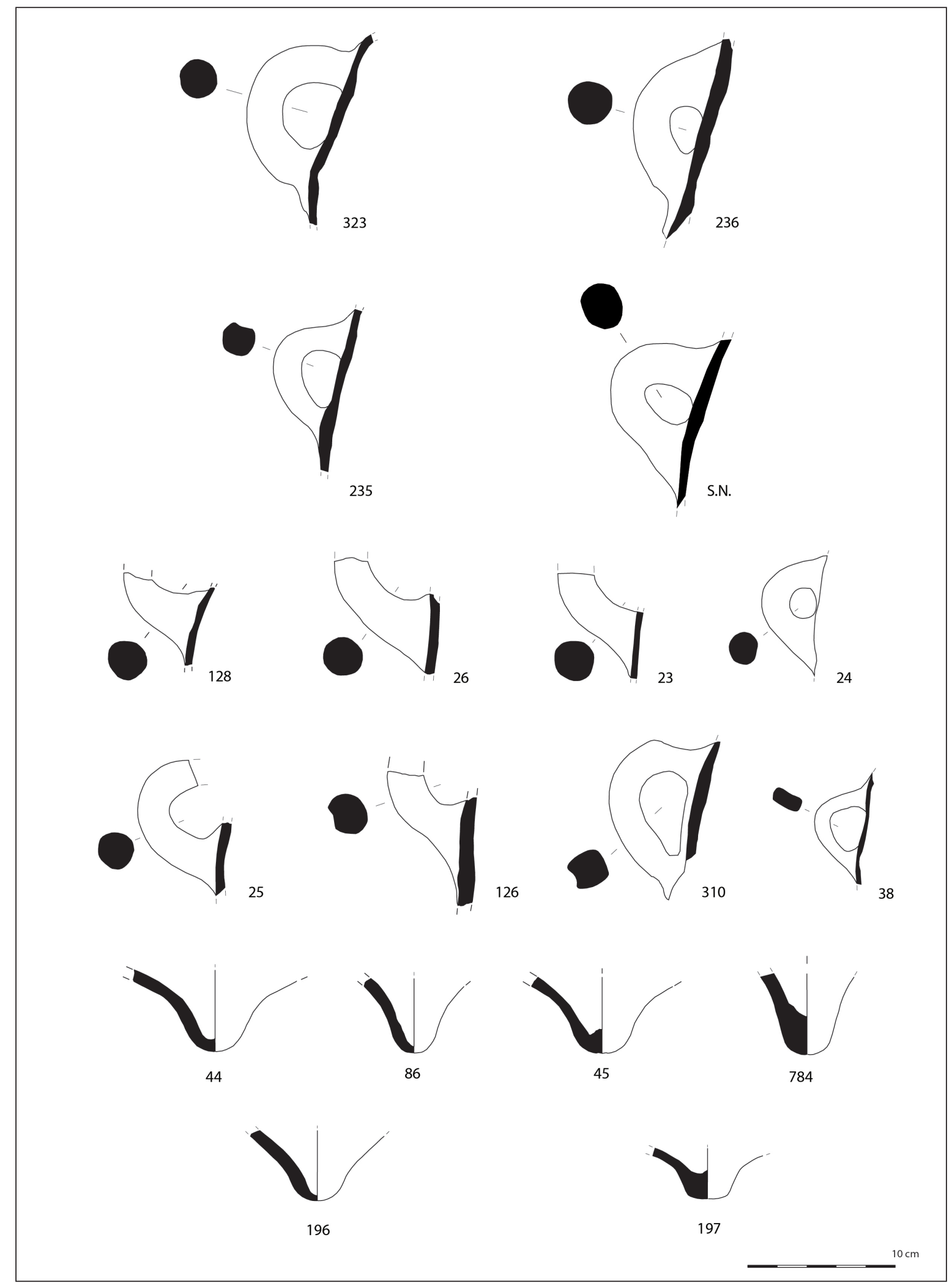

Figura 13. Fragmentos de asas e fundos de ânforas recolhidos no Porto do Sabugueiro. 


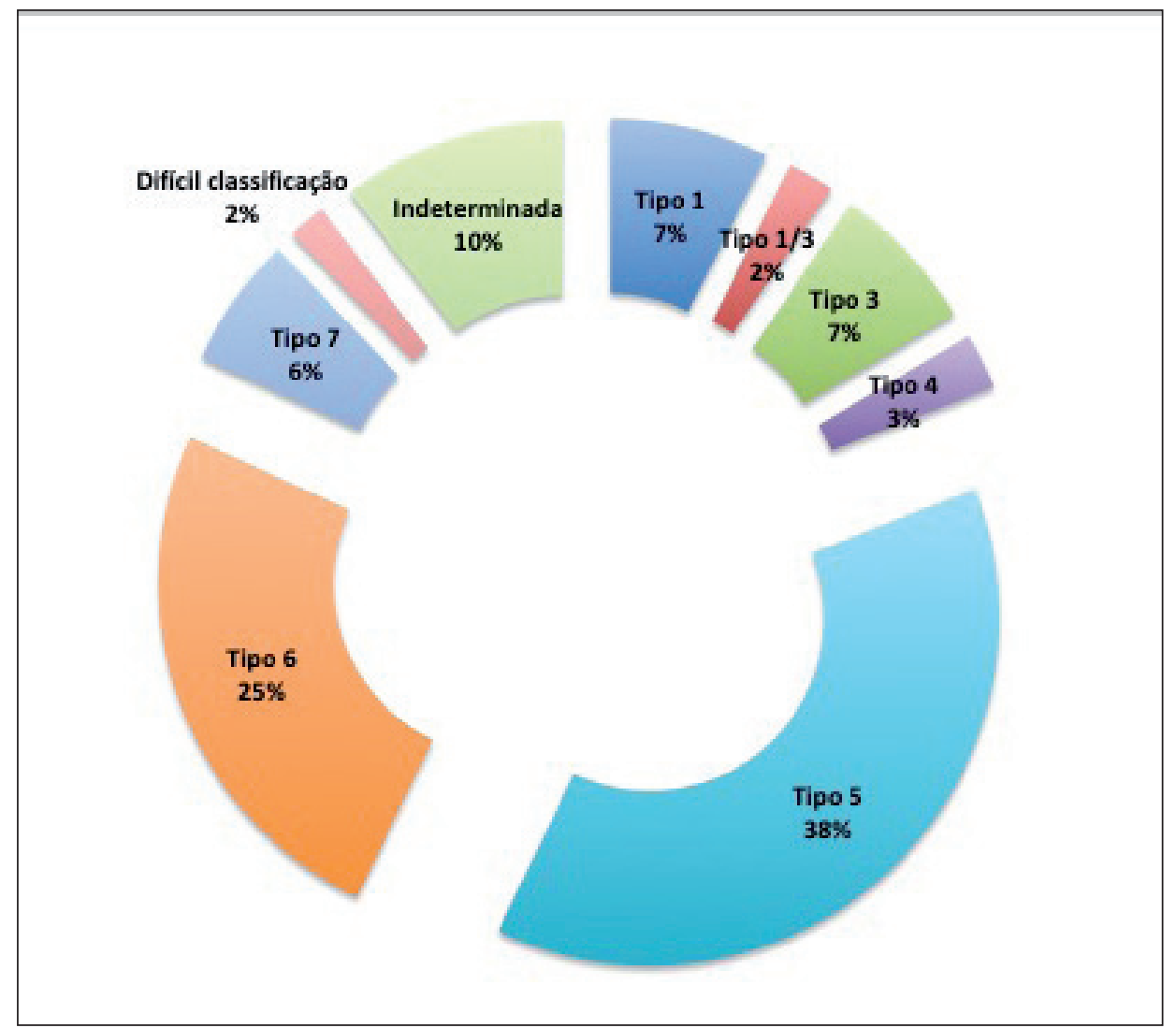

Figura 14. Gráfico de distribuição das produções locais/ regionais de acordo com os tipos morfológicos

As restantes importações são um pouco mais problemáticas de analisar. O fragmento que classificámos, ainda que com algumas reservas, como tipo Pellicer D, e que é, muito possivelmente também, originário do Baixo Guadalquivir, tem uma cronologia que se inicia em momentos avançados do século IV a.n.e., mas permanece nos inventários até momentos avançados do período romano-republicano. Assim, é muito difícil determinar se esta ânfora terá chegado ao Porto de Sabugueiro durante a Idade do Ferro ou já durante o século II ou inícios do I a.n.e.. Deve, contudo, referir-se que as ânforas do tipo Pellicer D produzidas na Andaluzia são muito raras na região, conhecendo-se, até ao momento, apenas o caso da Quinta do Almaraz (Olaio 2018), infelizmente, e também neste caso, sem dados contextuais.

Uma situação similar aplica-se ao fragmento que classificámos como 8.1.1.2, aparentemente produzido na Campiña Gaditana, e que seria um dos primeiros exemplares desta morfologia a ser reconhecido no estuário do Tejo. Trata-se de uma forma que começa a ser produzida a partir do século IV a.n.e., tendo-se assumido que não ultrapassaria o final da centúria seguinte (Carretero Poblete 2004). Contudo, o estudo de conjuntos artefactuais recuperados no ocidente do Algarve tem vindo a revelar quantidades consideráveis de ânforas do tipo 8.1.1.2 em contextos de finais do século II / inícios do século I a.n.e., o que tem levantado algumas questões sobre a cronologia do final da sua produção (Arruda e Sousa 2013; Sousa et al. 2016).

Assim, e apesar de estes dois últimos tipos (tipo Pellicer D e 8.1.1.2) serem tradicionalmente agregados às fases finais da Idade do Ferro, não devemos associar, inequivocamente, estas evidências ao período pré-romano, devendo ter-se em consideração a possibilidade de estas terem chegado à região já no quadro da integração da área do Tejo nos circuitos comerciais de época romano-republicana. Mais uma vez, só dados contextuais mais seguros poderão dar resposta a esta questão.

De qualquer forma, o conjunto de ânforas da Idade do Ferro e de tradição pré-romana do Porto do Sabugueiro fornece dados importantes sobre a produção e distribuição destes contentores nas áreas do curso médio e superior do estuário do Tejo. Ainda que não 


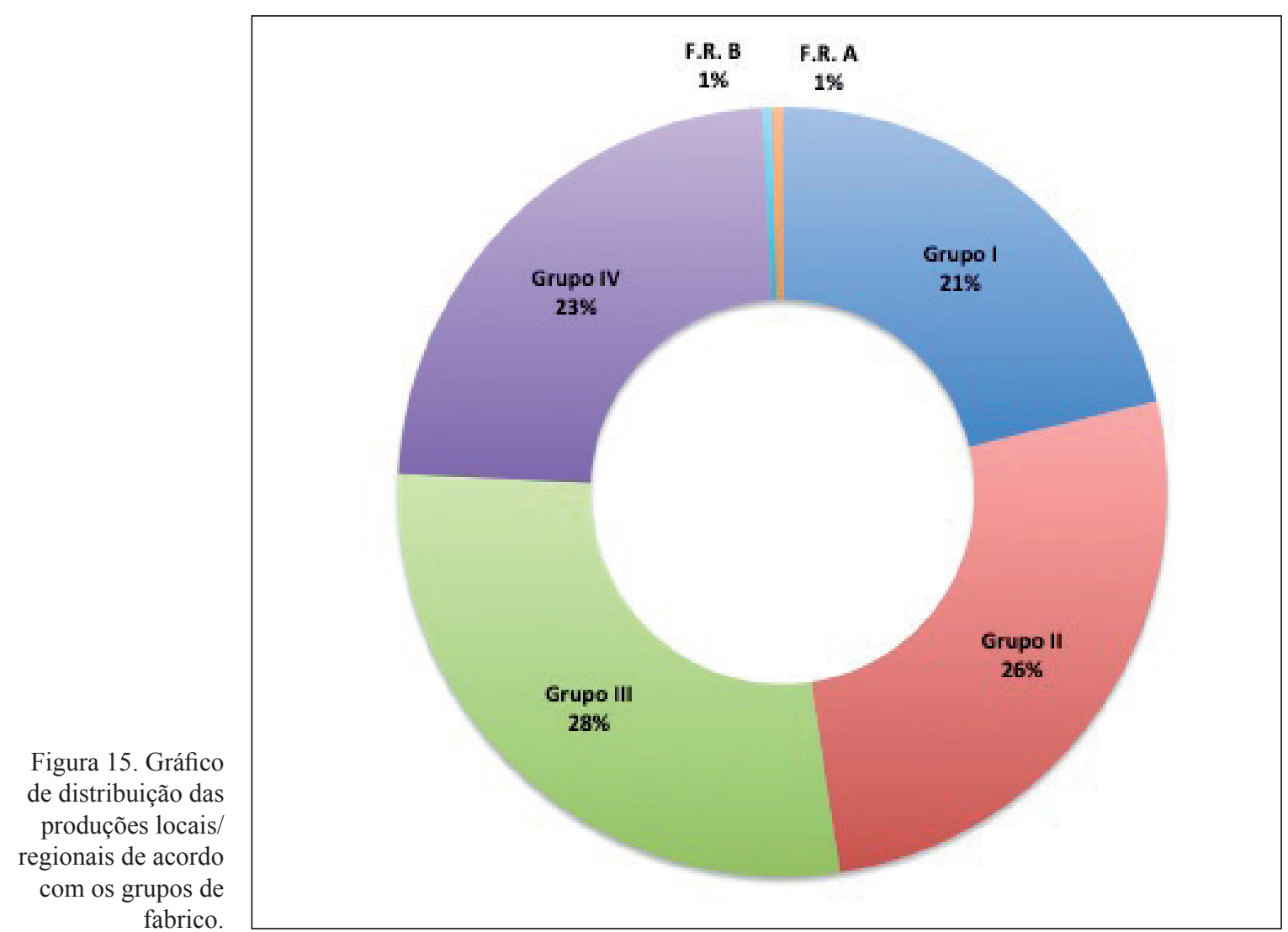

possamos deixar de lamentar a inexistência de dados contextuais, estes materiais mostram, sem qualquer dúvida, a importância que este sítio terá desempenhado ao longo do primeiro milénio no quadro da rede de povoamento deste território.

O estudo da complexidade das redes de produção e distribuição de contentores anfóricos no estuário do Tejo, ainda que tendo uma extensão essencialmente regional, podendo definir-se como uma espécie de circuito fechado, encontra-se ainda numa fase preliminar. Como já foi referido anteriormente, a importância e a dimensão deste fenómeno foram reconhecidas apenas durante os últimos cinco anos, sendo absolutamente necessário desenvolver os estudos tipológicos e arqueométricos que permitam conhecer, com mais detalhe, as suas especificidades. O trabalho que foi aqui apresentado é, assim, de primeira importância na correcta definição destas realidades: as características do conjunto, a sua representatividade quantitativa e a diversidade de produções identificadas é um contributo essencial para entender a grande complexidade que a produção e comercialização de contentores anfóricos atingiu, no estuário do Tejo, durante o $1^{\circ}$ milénio a.n.e.

\section{Agradecimentos}

Este trabalho foi realizado no âmbito do Projecto FETE - Fenícios no Estuário do Tejo (PTDC/EPH-ARQ/4901/2012), financiado pela Fundação para a Ciência e a Tecnologia.

\section{BIBLIOGRAFIA}

Aitchison, J. (1983): "Principal Component Analysis of Compositional Data”. Biometrika 70-1: 57-65.

Aitchison, J. (1984): "Reducing the dimensionality of compositional data sets". Mathematical Geology 16-6: 617-635.

Aldazábal, V.; Plá, R. e Ivernizzi, R. (2010): “Determinación de elementos traza en cerámicas arqueológicas del Lago Traful. Áreas de aprovisionamiento y circulación", in S. Bertolino, R. Cattáneo e A. D. Izeta (eds.), Arqueometría en Argentina y Latinoamérica: 29-34. Córdoba, Universidad Nacional de Córdoba.

Arruda, A. M. (2000): Los Fenicios en Portugal. Fenicios y mundo indígena en el centro y sur de 
Portugal (siglos VIII-VI a.C.). Barcelona, Universitat Pompeu Fabra.

Arruda, A. M.; Pereira, C.; Pimenta, J.; Sousa, E.; Mendes, H. e Soares, R. (2016): “As contas de vidro do Porto do Sabugueiro (Muge, Salvaterra de Magos, Portugal)". Cuadernos de Prehistoria y Arqueología de la Universidad Autónoma de Madrid 42: 79-101. <http://dx.doi.org/10.15366/ cupauam2016.42.002>.

Arruda, A. M.; Pereira, C.; Sousa, E.; Pimenta, J.; Detry, C. e Gomes, J. (2018): “Chões de Alpompé (Vale de Figueira, Santarém): Lendas e Narrativas”. Spal 27-2: 201-227. <http://dx.doi.org/10.12795/ spal.2018i27.20>.

Arruda, A. M. e Sousa, E. (2013): “Ânforas Republicanas de Monte Molião (Lagos, Algarve, Portugal)". Spal 22: 101-141. <https://doi.org/10.12795/ spal.2013.i22.05>.

Arruda, A. M.; Sousa, E.; Pimenta, J.; Mendes, H. e Soares, R. (2014): "Alto do Castelo's Iron Age occupation (Alpiarça, Portugal)". Zephyrus 74: 143-155 <http://dx.doi.org/10.14201/zephyrus201474143155>

Arruda, A. M.; Sousa, E.; Barradas, E.; Batata, C.; Detry, C. e Soares, R. (2017): “O Cabeço Guião (Cartaxo - Portugal): um sítio da Idade do Ferro do Vale do Tejo", in S. Celestino Pérez e E. Rodríguez González (eds.), Territorios comparados: los valles del Guadalquivir, el Guadiana y el Tajo en época tartesica: 319-361. Mérida, CSIC.

Barros, L. e Soares, A. M. (2004): “Cronologia absoluta para a ocupação orientalizante da Quinta do Almaraz, no estuário do Tejo (Almada, Portugal)". $O$ Arqueólogo Português série IV 22: 333-352.

Baxter, M. J. (1994): Exploratory Multivariate Análisis in Archaeology. Edinburgh, Edinburgh University Press.

Baxter, M. J. (2003): Statistics in Archaeology. London, Arnold Publishers.

Cardoso, J. L.; Arruda, A. M.; Sousa, E. e Rego, M. (2014): “Outorela I e Outorela II, dois pequenos sítios da Idade do Ferro a norte do Estuário do Tejo (concelho de Oeiras)". Estudos Arqueológicos de Oeiras 21: 393-428.

Cardoso, J. L. e Carreira, J. R. (1997-1998): “A ocupação de época púnica da Quinta da Torre (Almada)". Estudos Arqueológicos de Oeiras 7: 189-217.

Cardoso, J. L. e Silva, C. T. (2013): “O casal agrícola da Idade do Ferro de Gamelas 3 (Oeiras)". O Arqueólogo Português série V 2: 353-398.

Cardoso, G. (1991): Carta Arqueológica do Concelho de Cascais. Cascais, Câmara Municipal.
Cardoso, G. e Encarnação, J. (2013): “O povoamento pré-romano de Freiria - Cascais". Cira-Arqueologia 2: 133-180.

Carmona, N.; García-Heras, M.; Villegas, M. A.; Fernández-Posse, M.D. e Sánchez-Palencia, F. J. (2008): "Producción cerámica en Las Médulas (León). Una comparación diacrónica a través de métodos arqueométricos", in S. Rovira Llorens, M. García-Heras, M. Gener Moret e I. Montero Ruiz (eds.), Actas VII Congreso Ibérico de Arqueometría: 277-287. Madrid (2007), Madrid, Quadro.

Carretero Poblete, P. A. (2004): Las ánforas tipo "Tiñosa" y la explotación agrícola de la CampiñaGaditana entre los siglos Vy III a.C. Tese de doutoramento, Universidad Complutense de Madrid. Inédita.

Coll Conesa, J. (2000): "Aspectos de tecnolocía de producción de la cerámica ibérica", in C. Mata Parreño e G. Pérez Jordá (eds.), IBERS. Agricultors, artesans i comerciants. III Reunió sobre Economia en el Món lbèric (Saguntvm-PLAV Extra-3): 191-209. Valencia, Universitat de Valencia.

De la Fuente, G. A. e Vera S. D. (2013): "Evidencias de sobrecocción y vitrificación en las estructuras de combustión (hornos de cerámica) y en cerámica arqueológica procedentes del sitio Costa de Reyes $\mathrm{N}^{\mathrm{o}}$ 5: Una aproximación a través de la petrología cerámica, MEB-EDS y difracción de rayos x (Dpto. Tinogasta, Provincia de Catamarca, Noroeste, Argentina)", in E. F. Irassar e E. Aglietti (coords.), Actas del XI Congreso y Exposición Internacional de la Industria Cerámica, del Vidrio, Refractarios y Suministros (Olavarria 2013): ATACER 2013: 351356. Tandil, Universidad Nacional del Centro de la Provincia de Buenos Aires.

Diogo, A. M. D. (1993): “Ânforas pré-romanas dos Chões de Alpompé (Santarém)". Estudos Orientais IV: 215-227.

Galván Martínez, V. (1995): “Almizaraque: correlación entre geoquímica y tipos cerámicos". Complutum 6 : 319-327.

García Fernández, F. (2019): "Rumbo a poniente: el comercio de ánforas turdetanas en la costa atlántica de la península ibérica (siglos V-I a.C.). Archivo Español de Arqueología 92: 119-153 <https://doi. org/10.3989/aespa.092.019.007>.

Glasckoc, M. D. (1992): "Neutron Activation Analysis", in H. Neff (ed.), Chemical characterization of ceramic pastes in archaeology: 11-26. Madison, Prehistory Press.

Gómez Siurana, M. D. (1987): Caracterización de cerámicas arqueológicas de la provincia de Alicante 
por aplicación de análisis estadístico multivariable a los datos de composición química. Tese de doutoramento, Universidad de Alicante. Inédita.

Guerrero Ayuso, V. M. (1991): "El palacio-santuario de Cancho Roano (Badajoz) y la comercializacion de ánforas fenicias indígenas". Rivista di Studi Fenici 19-1: 49-81.

Nieuwendam, L. e Santos, R. (2008): "Villa romana de Vilares, Cascais. Trabalhos arqueológicos em 20072008". Al-madan online adenda electrónica. II série: 16 (http://www.almadan.publ.pt/16Adenda. htm, consultada a 27 de Junho de 2019).

Olaio, A. (2018): "O povoado da Quinta do Almaraz (Almada, Portugal) no âmbito da ocupação no Baixo Tejo durante o $1^{\circ}$ milénio a.n.e.: os dados do conjunto anfórico". Spal 27-2: 125-163 <http://dx. doi.org/10.12795/spal.2018i27.18>.

Pellicer Catalán, M. (1978): “Tipología y cronología de las ánforas prerromanas del Guadalquivir según el Cerro Macareno (Sevilla)". Habis 9: 365-400.

Pereira, M. A. H. (1975): "Objectos Egípcios do Porto do Sabugueiro (Muge)". Conímbriga XIV: 173-176.

Pereira, M. (2017): "Os cossoiros de Porto de Sabugueiro (Muge, Salvaterra de Magos)". Cira - Arqueologia 5: 55-75.

Pimenta, J. (2005): As ânforas romanas do Castelo de São Jorge (Lisboa). Trabalhos de Arqueologia 41. Lisboa, Instituto Português de Arqueologia.

Pimenta, J.; Calado, M. e Leitão, M. (2005): "Novos dados sobre a ocupação pré-romana da cidade de Lisboa: as ânforas da sondagem n. ${ }^{\circ} 2$ da Rua de São João da Praça". Revista Portuguesa de Arqueologia 8-2: 313-334.

Pimenta, J. e Mendes, H. (2008): "Descoberta do povoado pré-romano de Porto do Sabugueiro (Muge)". Revista Portuguesa de Arqueologia 11-2: 171-194.

Pimenta, J. e Mendes, H. (2011): "Novos dados sobre a presença fenícia no vale do Tejo. As recentes descobertas na área de Vila Franca de Xira". Estudos Arqueológicos de Oeiras 18: 591-618.

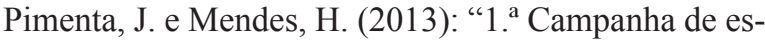
cavações arqueológicas no povoado pré-romano de Porto do Sabugueiro - Muge - Salvaterra de Magos". Cira Arqueologia 2: 195-219.

Pimenta, J. e Mendes, H. (2015): "Casal dos Pegos I e o Povoamento Orientalizante do Rio da Silveira Vila Franca de Xira". Cira-Arqueologia 4: 19-54.

Pimenta, J.; Mendes, H. e Madeira, F. (2010): "O povoado pré-romano de Castanheira do Ribatejo, Vila Franca de Xira". Revista Portuguesa de Arqueologia 13: 25-56.
Pimenta, J.; Mendes, H.; Arruda, A. M.; Sousa, E. e Soares, R. (2014a): "Do pré-romano ao Império: a ocupação humana do Porto do Sabugueiro (Muge, Salvaterra de Magos)". Magos. Revista Cultural do Concelho de Salvaterra de Magos 1: 39-58.

Pimenta, J.; Silva, R. e Calado, M. (2014b): "Sobre a ocupação pré-romana de Olisipo. A intervenção arqueológica urbana da Rua de São Mamede ao Caldas n. ${ }^{\circ}$ 15", in A. M. Arruda (ed.), Fenícios e Púnicos, por terra e mar. Actas do VI Congresso Internacional de Estudos Fenícios e Púnicos (Lisboa 2005): vol. 2 712-723. Lisboa, Centro de Arqueologia da Universidade de Lisboa.

Pimenta, J.; Gaspar, A.; Gomes, A.; Mota, N. e Miranda, P. (2014c): "O estabelecimento romano-republicano de Olisipo: estrutura e contextos do Beco do Forno do Castelo, Lote 40 - Lisboa". Cira Arqueologia 3: 122-148.

Pimenta, J.; Sousa, E.; Mendes, H.; Henriques, E. e Arruda, A. M. (2018): "A Eira da Alorna (Almeirim): as ocupações pré e proto-históricas". Cira Arqueologia 9: 9-49.

Ramon Torres, J. (1995): Las Ánforas Fenicio-Púnicas del Mediterráneo Central y Occidental. Barcelona, Publicacions Universitat de Barcelona.

Rodrigues, M.; Pimenta, J.; Sousa, E.; Mendes, H. e Arruda, A. M. (no prelo): "A cerâmica cinzenta de Porto do Sabugueiro (Muge, Portugal)". Cira-Arqueologia.

Silva, C. T. e Soares, J. (2012): "Castro de Chibanes (Palmela). Do III milénio ao século I a.C.", in Palmela Arqueológica no Contexto da Região Interestuarina Sado-Tejo: 67-87. Palmela, Câmara Municipal.

Sousa, E. (2014): A ocupação pré-romana da foz do Estuário do Tejo. Lisboa, Centro de Arqueologia da Universidade de Lisboa.

Sousa, E. (2017): "Percorrendo o Baixo Tejo: Regionalização e Identidades Culturais na $2^{\mathrm{a}}$ metade do $1^{\circ}$ milénio a.C.”, in S. Celestino Pérez e E. Rodríguez González (eds.), Territorios comparados: los valles del Guadalquivir, el Guadiana y el Tajo en época tartesica: 295-318. Mérida, CSIC.

Sousa, E.; Alves, C. e Pereira, T. (2016): "O conjunto anfórico da urbanização do Moleão, Lagos (Portugal)", in R. Járrega e P. Berni (eds.), Amphorae ex Hispania: paisajes de producción y consumo: 464478. Tarragona, ICAC.

Sousa, E. e Arruda, A. M. (2018): “A I Idade do Ferro na Alcáçova de Santarém (Portugal): os resultados da campanha de 2001". Onuba 6: 57-95. 
Sousa, E. e Guerra, S. (2018): “A presença fenícia em Lisboa: novos vestígios descobertos no alto da colina do Castelo de São Jorge". Saguntum 50: 57-88. DOI: $10.7203 /$ SAGVNTVM.50.10636

Sousa, E. e Pimenta, J. (2014): "A produção de ânforas no Estuário do Tejo durante a Idade do Ferro", in R. Morais, A. Fernández e M. J. Sousa (eds.), As Produções Cerâmicas de Imitação na Hispânia. Monografias Ex Officina Hispana II: vol. 1 303-316. Porto, Faculdade de Letras da Universidade do Porto.
Sousa, E.; Pimenta, J.; Mendes, H. e Arruda, A. M. (2017): "A ocupação Proto-Histórica do Alto dos Cacos (Almeirim, Portugal)". Cira - Arqueologia 5: 9-32.

Whallon, R. (1990): "Defining structure in clustering dendrograms with multilevel clustering", in A. Voorips e B. Ottaway (eds.), New tools for mathematical Archaeology: 1-13. Cracow, Polish Academy of Sciences. 